\title{
YUCCA-Mediated Biosynthesis of the Auxin IAA Is Required during the Somatic Embryogenic Induction Process in Coffea canephora
}

\author{
Miguel A. Uc-Chuc ${ }^{1}$, Cleyre Pérez-Hernández ${ }^{1}$, Rosa M. Galaz-Ávalos ${ }^{1}$, Ligia Brito-Argaez ${ }^{1}$, \\ Víctor Aguilar-Hernández ${ }^{2}(\mathbb{D})$ and Víctor M. Loyola-Vargas ${ }^{1, *(\mathbb{D})}$ \\ 1 Unidad de Bioquímica y Biología Molecular de Plantas, Centro de Investigación Científica de Yucatán, \\ A.C. Calle 43 No. $130 \times 32$ y 344 Col. Chuburná de Hidalgo, Mérida C.P. 97205, Mexico; \\ miguel.uc@cicy.mx (M.A.U.-C.); cleyre_aph@hotmail.com (C.P.-H.); \\ gaar@cicy.mx (R.M.G.-Á.); lbrito@cicy.mx (L.B.-A.) \\ 2 Catedrático CONACYT, Unidad de Bioquímica y Biología Molecular de Plantas, Centro de Investigación \\ Científica de Yucatán, Mérida C.P. 97205, Mexico; victor.aguilar@cicy.mx \\ * Correspondence: vmloyola@cicy.mx
}

Received: 18 June 2020; Accepted: 28 June 2020; Published: 3 July 2020

\begin{abstract}
Despite the existence of considerable research on somatic embryogenesis (SE), the molecular mechanism that regulates the biosynthesis of auxins during the SE induction process remains unknown. Indole-3-acetic acid (IAA) is an auxin that is synthesized in plants through five pathways. The biosynthetic pathway most frequently used in this synthesis is the conversion of tryptophan to indol-3-pyruvic acid (IPA) by tryptophan aminotransferase of Arabidopsis (TAA) followed by the conversion of IPA to IAA by enzymes encoded by YUCCA (YUC) genes of the flavin monooxygenase family; however, it is unclear whether YUC-mediated IAA biosynthesis is involved in SE induction. In this study, we report that the increase of IAA observed during SE pre-treatment (plants in MS medium supplemented with 1-naphthaleneacetic acid (NAA) $0.54 \mu \mathrm{M}$ and kinetin (Kin) $2.32 \mu \mathrm{M}$ for 14 days) was due to its de novo biosynthesis. By qRT-PCR, we demonstrated that YUC gene expression was consistent with the free IAA signal found in the explants during the induction of SE. In addition, the use of yucasin to inhibit the activity of YUC enzymes reduced the signal of free IAA in the leaf explants and dramatically decreased the induction of SE. The exogenous addition of IAA restored the SE process in explants treated with yucasin. Our findings suggest that the biosynthesis and localization of IAA play an essential role during the induction process of SE in Coffea canephora.
\end{abstract}

Keywords: auxin; Coffea canephora; localization; somatic embryogenesis; YUCCA; yucasin

\section{Introduction}

Plants, unlike animals, have a high capacity for regeneration of new individuals identical to the mother from a cell or groups of cells without the need for fertilization. This regeneration mechanism is known as somatic embryogenesis (SE) [1,2]. SE is the development of structures similar to a zygotic embryo from somatic cells $[3,4]$. It can also be the process by which somatic cells, under induction conditions, generate competent cells that undergo a series of morphological, biochemical, and molecular changes to give rise to somatic embryos without the fusion of gametes [5]. SE provides an invaluable tool for the genetic improvement of plant species that cannot be propagated sexually [6].

The study of the biochemical and molecular mechanisms of SE allows us to identify the factors involved in SE induction [6] and to determine how best to apply them to the genetic improvement of a range of plant species [6,7]. Furthermore, SE is an example of totipotency because the somatic 
cells respond directly to a stimulus, leading to the development and formation of the somatic embryo. Therefore, SE is an excellent system for the study of cellular differentiation and dedifferentiation [8].

$\mathrm{SE}$ is a complex process that involves many factors, including plant species, tissue type (explant), culture medium, exogenous and endogenous growth regulators, and nitrogen and carbon sources $[2,9,10]$. In addition, somatic cells can activate the genetic machinery necessary for the transcription of genes involved in SE induction [11], implicating the alteration of cell wall composition and changes in growth regulators, gene expression, and epigenetic regulations in this process [12].

It has been proposed that plant growth regulators, mainly indole-3-acetic acid (IAA), play a crucial role in mediating the signal transduction that leads to the reprogramming of gene expression. This change is followed by a series of cell divisions that induce disorganized growth (callus) or lead directly to SE [13]. IAA is a molecule that controls almost all aspects of plant growth and development [14]. Its biosynthesis is crucial for plant homeostasis, including embryo development, fruit ripening, organogenesis, and plant architecture $[15,16]$. However, the action of auxin is determined by its synthesis and distribution in tissue, mainly via its polar transport from cell to cell $[17,18]$.

The route most conserved and providing the most direct way to produce IAA in plants is from tryptophan via two enzymatic reactions consisting of tryptophan aminotransferase of Arabidopsis (TAA) and YUCCA (YUC) flavin monooxygenase of the indole-3-pyruvic acid (IPA) pathway [14,19-21].

Genetic studies have demonstrated that YUC functions as the rate-limiting step of the IPA pathway, indicating that YUC plays a crucial role in developmental processes regulated by cellular IAA levels [14]. Biochemical and molecular studies have shown that these gene families (TAA and YUC) participate in the pathway of IAA biosynthesis in several plant species, including Arabidopsis thaliana, Zea mays, and Oryza sativa [22,23]. It has been reported that IAA biosynthesis through YUC is necessary for the establishment of the basal part of the embryo and onset of embryonic organs [24]. Previous findings indicated that the location of auxin biosynthesis plays an essential role in many growth and development processes, including embryogenesis [25].

Cheng et al. [26] overexpressed YUC1, YUC2, YUC4, and YUC6 genes, and their results indicated an increase in the production of auxin in Arabidopsis seedlings [26]. In addition, they determined the expression of YUC1 and YUC4 at the apical meristem and primordia of young leaves [24,26]. Single or double mutants showed no adverse effect, unlike quadruple mutants, which showed severe effects in the development of the seedlings [24]. Accordingly, due to redundant functions of the YUC genes family it is difficult to access reverse genetic approaches to understand the physiological role of IAA biosynthesis [14]. Hence, the use of specific inhibitors to overcome the redundant activity of target genes has emerged as a useful tool for genetic studies [14].

Despite the various studies in this area, the genes regulating IAA auxin biosynthesis during embryogenesis are not known [24], and endogenous intracellular levels remain unclear during the SE induction process. Apparently, de novo IAA biosynthesis plays an essential role in SE, because previous reports have shown that auxin biosynthesis is dynamic during embryogenesis [27].

Our primary goal in this work was to determine whether YUC-mediated IAA biosynthesis is involved in the SE induction process in Coffea canephora. To answer this question, we used RT-qPCR to measure the transcription levels of $C c Y U C$ and used a specific yucasin inhibitor to block the biosynthesis of the auxin IAA. Yucasin is a powerful specific YUC enzyme inhibitor [28].

In this study, we found that CcYUC1, CcYUC1-putative, CcYUC4, and CcYUC-like have dynamic expression patterns at the moment of the induction of the SE process. We showed that there exists a correlation between the CCYUC expression pattern and the location of the free IAA auxin signal at the beginning of the induction of the SE process. Furthermore, the formation of a local endogenous IAA gradient in specific tissues was crucial during the SE induction process in C. canephora. On the other hand, treatment with yucasin inhibited SE, but exogenous IAA addition restored the embryogenic process. Our data showed that the YUC-mediated IAA biosynthesis is crucial for SE in C. canephora. 


\section{Results}

2.1. The Induction Process, Histology, and Expression Profiling of the CcYUCs Transcribed during SE in C. canephora

The pre-treatment stage (plants in MS medium supplemented with NAA $0.54 \mu \mathrm{M}$ and Kin $2.32 \mu \mathrm{M}$ for 14 days) and growth regulators are essential for SE in C. canephora. To induce SE, we used foliar explants of plantlets maintained in Murashige and Skoog (MS) medium for 14 days under photoperiod conditions (see Materials and Methods). The explants were then transferred to an auxin-free medium supplemented with benzyladenine (BA, $5 \mu \mathrm{M})$. The samples were collected 56 days after induction (dai) (Figure 1A) and the number of somatic embryos was counted (Figure 1B). During the induction process, we observed a rapid proliferation of proembryogenic cell mass at the edge of the explant wound 14, 21, and 28 dai. By 56 dai, all the developmental stages of the somatic embryos were found (G, globular; H, heart; T, torpedo; and C, cotyledonary; Figure 1A). The total embryo production per flask was 402.3 . A total of 298 were embryos in the $\mathrm{G}$ stage, followed by 48.6 embryos in the $\mathrm{H}$ stage, 31.3 in the T stage, and 24.3 in the $C$ stage (Figure 1B).

A

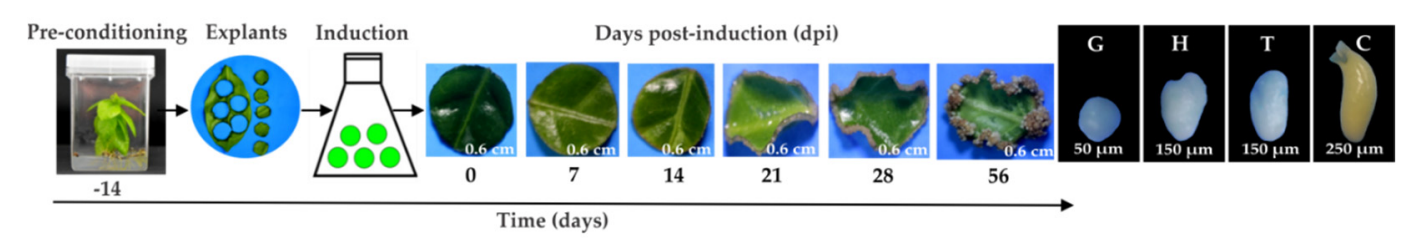

B

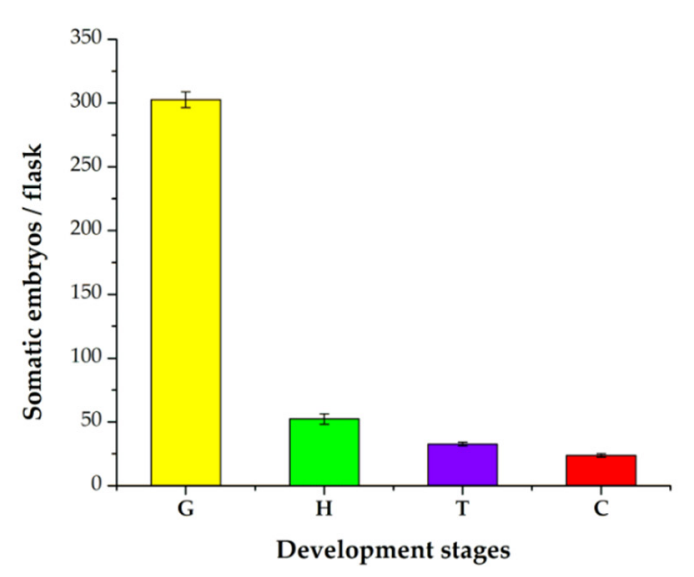

Figure 1. SE induction process in C. canephora. (A), On Day-14 (beginning of the pre-treatment), C. canephora plantlets were incubated in a pre-treatment medium (MS medium supplemented with NAA $0.54 \mu \mathrm{M}$ and Kin $2.32 \mu \mathrm{M}$ ) for 14 days. After 14 days, explants were transferred into the induction medium (Yasuda medium supplemented with $5 \mu \mathrm{M}$ benzyladenine) under photoperiod conditions (16/8 h) for 56 dai. (B), Total embryo production per flask was 402.3. The values corresponding to the different developmental stages were globular $(G, 298)$, heart $(H, 48.6)$, torpedo $(T, 31.3)$, and cotyledonary $(C, 24.3)$. The bars over the columns represent the mean value \pm standard error of three independent experiments.

Transversal cuts of the explants were analyzed during the SE induction process, in order to observe the changes that are carried out in the explant and the formation of the first embryogenic structures. The results showed that at the beginning, the explant tissues were composed of spongy and palisade mesophyll cells (Figure 2A). The structure of the explants showed almost no change during the first 14 days of the induction of SE (Figure 2B,C). After 21 days in the induction medium, the first embryogenic cells appeared. These first structures were located near the vascular tissue (Figure 2D). 
These new cells were small, circular, and had a very dense cytoplasm (Figure 2E). Twenty-eight dai, there was an increase in the proembryogenic mass, with most of the mass emerging from spongy mesophyll cells (Figure 2F). The formation of proembryos is the result of the coordinated growth of a series of organized cell divisions that will give rise to somatic embryos.
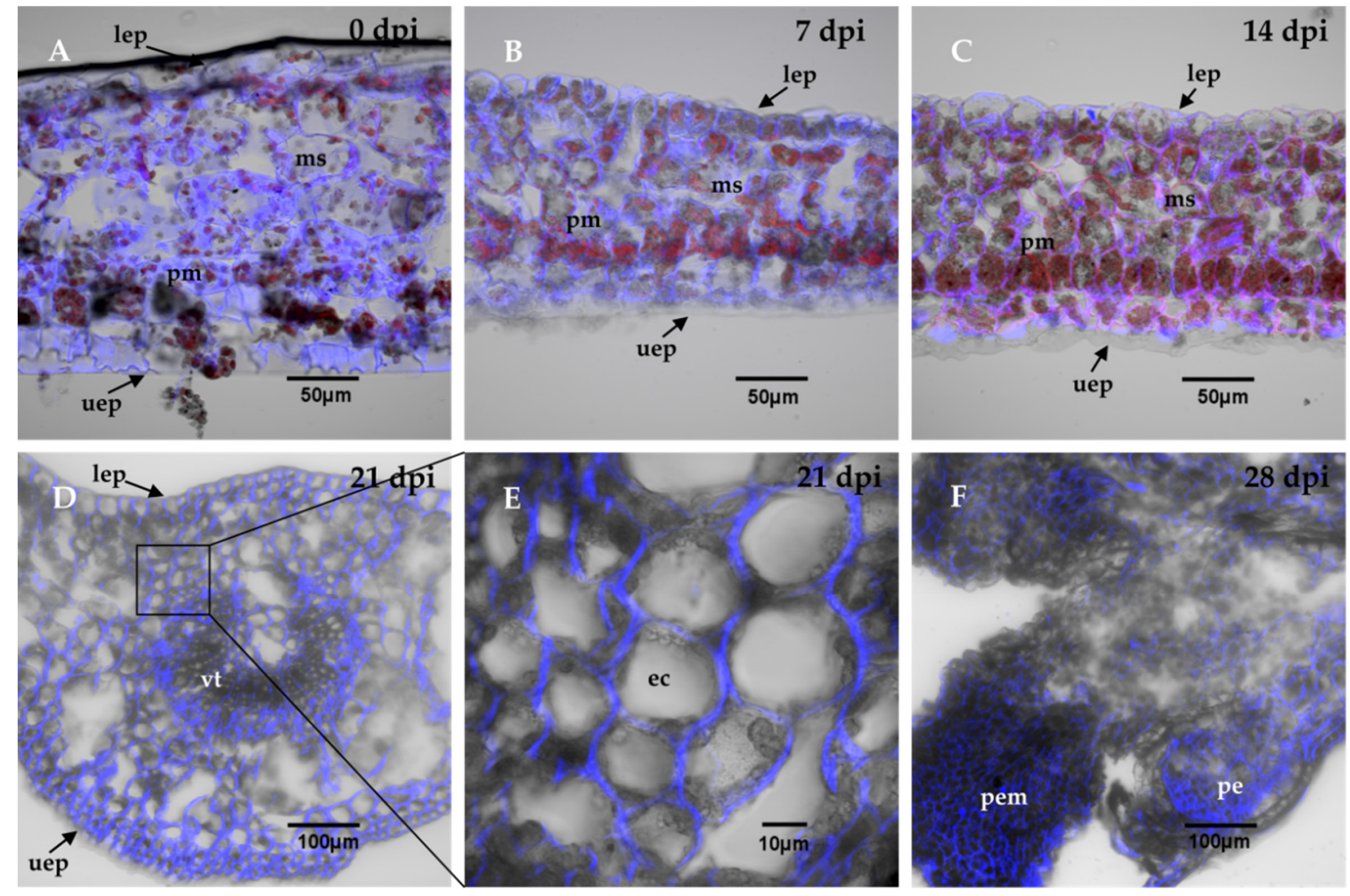

Figure 2. Histological analysis during the SE induction process in C. canephora. The leaf explants were composed of parenchymal cells of the spongy mesophyll, sm, and palisade mesophyll, pm. There were no changes in the explant cell structure, as shown in panel (A), which corresponds to the induction day (0 day); (B), 7 dai, and (C), 14 dai. (D), From 21 dai, the appearance of embryogenic cells, ec, was observed near the vascular tissue, vt. (E), a close-up view of the explants 21 dai showed dense embryogenic cells. (F), 28 dai, the proembryos, pe, were formed. The cell wall was stained with calcofluor white and chlorophyll is indicated in red. Other abbreviations: proembryogenic mass: pem; upper epidermis: uep; lower epidermis: lep. 0, 7, 14, 21, 28 dai of SE $30 \mu \mathrm{m}$ cross-sections.

\subsection{Identification and Content of Free IAA and Conjugated IAA}

IAA is found in cells in free and conjugated form. In all the systems in which IAA conjugates have been measured, they are more than $90 \%$ of the total auxin. We used liquid chromatography-mass spectrometry (LC-MS/MS) and compared the retention times and fractionation patterns of standards and the auxins extracted from the explants. In this way, we identified free IAA and its conjugates with aspartic acid (Asp), glutamic acid (Glu), alanine (Ala), and leucine (Leu). The elution and fractionation patterns correspond perfectly between the standard and the samples (Supplementary Figures S1-S5). With this certainty, we proceeded to quantify the free IAA and its conjugates. The amount of IAA-Asp determined was only at the trace level, so the quantification was performed in the other three conjugates and free IAA (Figure 3). 


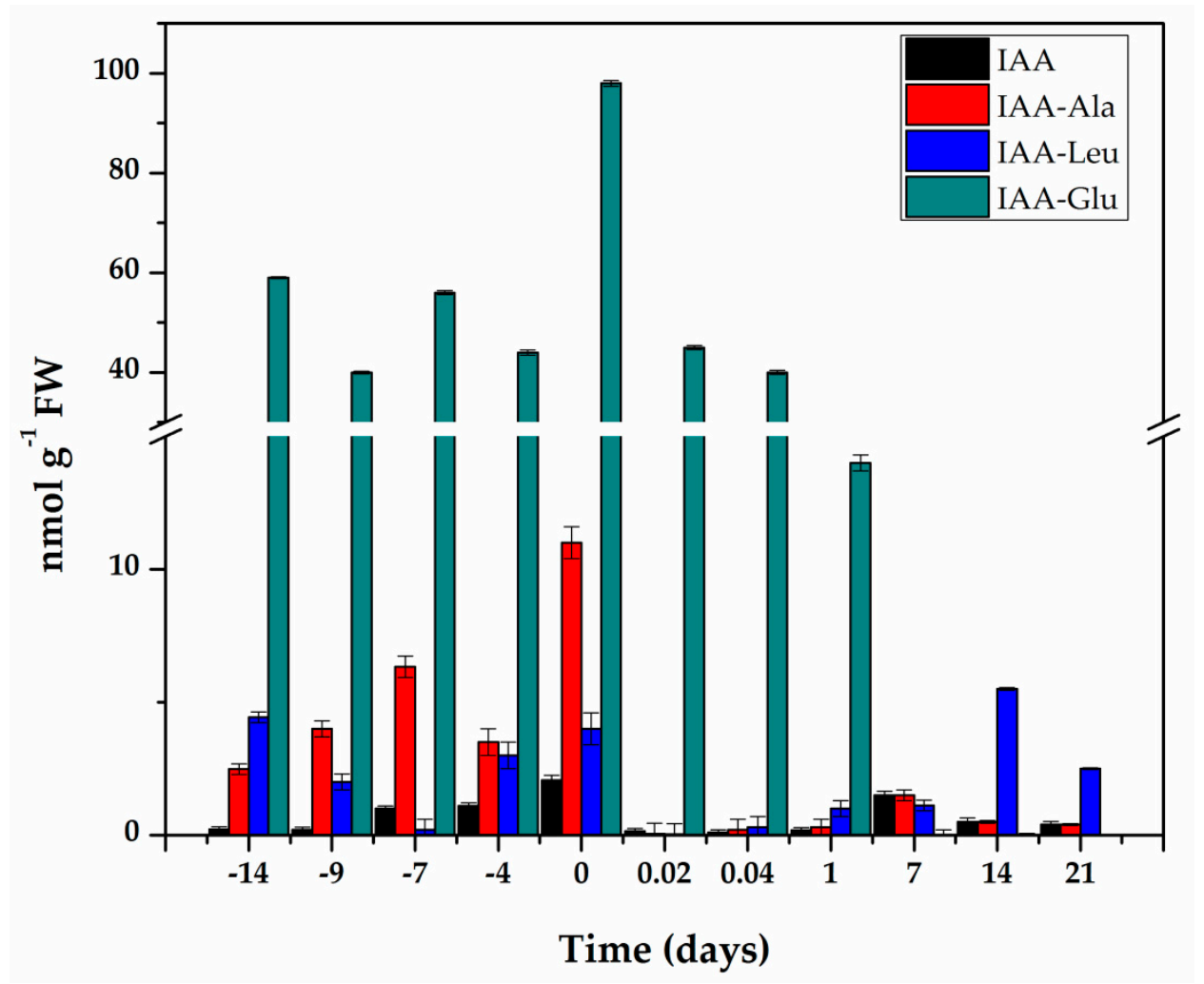

Figure 3. Content of IAA and its conjugates during pre-treatment and induction of SE in C. canephora. Samples of $100 \mathrm{mg}$ of leaf tissue were collected (Days-14, $-9,-4$, and 0). Samples were also collected at $0.02,0.04,1,7,14$, and 21 days after SE induction. Samples were analyzed as described in Materials and methods. All analyses were carried out with three biological replicates from at least two different experiments. The bars represent the standard error $(n=3)$.

The endogenous initial free IAA content was $0.22 \mathrm{nmol} \mathrm{g}^{-1} \mathrm{FW}$ and increased more than nine times during the pre-treatment of the seedlings in the presence of NAA and Kin (Figure 3), and reached a maximum content of $2.06 \mathrm{nmol} \mathrm{g}^{-1} \mathrm{FW}$ fourteen days after the start of the pre-treatment. The explants were taken from these plantlets to start the induction of SE. The free IAA content decreased rapidly during the first hour of explant incubation in the induction medium of the SE. and was maintained at levels of 0.1 to $0.5 \mathrm{nmol} \mathrm{g}^{-1} \mathrm{FW}$ for the next six days. Its level increased again with the appearance of the first embryonic structures.

IAA conjugates are a significant part of IAA homeostasis $[29,30]$, so they were assessed throughout the entire process (Figure 3). The conjugate with glutamic acid made up more than $85 \%$ of the total IAA content. Fourteen days of pre-treatment produced an endogenous level of $98 \mathrm{nmol} \mathrm{g}^{-1} \mathrm{FW}$ of IAA-Glu. After the induction of SE, the IAA-Glu content decreased seven times in just $24 \mathrm{~h}$ and practically disappeared seven days after the induction of SE.

The conjugates with alanine and leucine made up $12.6 \%$ of the total IAA. These conjugates are very important for homeostasis of IAA, since they can be hydrolyzed and contribute to free IAA. The IAA-Ala increased from $2.49 \mathrm{nmol} \mathrm{g}^{-1} \mathrm{FW}$ at the beginning of the pre-treatment to $11 \mathrm{nmol} \mathrm{g}^{-1}$ FW at the time of induction and decreased very quickly over the next 21 days. The IAA-Leu conjugate decreased during the first seven days of pre-treatment, and by the time of the induction of SE, had returned to its initial levels. This conjugate decreased very rapidly during the first hours of the induction of SE and then began to increase to levels ranging from 2.5 to $5.5 \mathrm{nmol} \mathrm{g}{ }^{-1} \mathrm{FW}$ in the following days (Figure 3).

To determine whether the increase in IAA content observed during pre-treatment of $C$. canephora seedlings was due to de novo biosynthesis, $3-{ }^{-14} \mathrm{C}-\mathrm{Trp}$ was used, as has been done in $A$. thaliana [31-33] and Solanum lycopersicum [34]. 
First, we performed standard thin-plate chromatography, and ran real non-radioactive samples and identified the compounds by LC-MS. This experiment gave us the confidence to associate radioactive spots with their identity. The result of incubation in the presence of $3-{ }^{14} \mathrm{C}$-tryptophan (Trp) can be seen in Table 1. As the days of the pre-treatment progressed, there was an increase in the radioactivity associated with the IAA. This result suggests that the IAA biosynthesis was de novo from Trp. A 7-fold increase in the IAA content was observed between Day-9 and Day 0 (Table 1). The marked Trp only began to accumulate on Days-4 and 0, possibly because the cells had reached a maximum biosynthesis of IAA.

Table 1. Total radioactivity present in each sample of C. canephora plantlets analyzed.

\begin{tabular}{cccccc}
\hline \multirow{2}{*}{ Sample } & \multicolumn{5}{c}{ Days } \\
\cline { 3 - 6 } & & $-\mathbf{9}$ & $-\mathbf{7}$ & $-\mathbf{4}$ & $\mathbf{0}$ \\
\hline \multirow{2}{*}{ Leaf extracts } & IAA & 154 & 174 & 274 & 1093 \\
Leaves in medium & Trp & 0 & 0 & 34 & 40 \\
Medium & 287 & 764 & 755 & 1131 \\
Stem & $2,306,388$ & $1,845,858$ & $1,537,818$ & $2,283,948$ \\
Root & - & - & - & 5860 \\
Total counts per minute & - & - & - & - \\
& & $2,306,829$ & $1,846,796$ & $1,538,848$ & $2,292,033$ \\
\hline
\end{tabular}

In an experiment using a radioactive label, it is important to determine the fate of the entire radioactive label. Therefore, we measured the radioactivity present in each of the fractions of the experiment. A part of the radioactivity was in the tissues and other part in the culture medium. In the case of tissues, radioactivity was not only determined in the explants used to induce SE, but also in the rest of the plant. The extraction of auxins present in the stem of the plants was also performed and their radioactivity was measured. From Days $-9,-7$, and -4 , the stem was not extracted because it was submerged in the liquid medium and it would not have been possible to determine how much radioactivity was due to the auxin present in the stem and how much radioactivity was external pollution; however, this determination was done on Day 0 . The seedlings were incubated in $10 \mathrm{~mL}$ of pre-treatment medium to which the radioactivity was added; of this, $10 \mu \mathrm{L}$ was taken to count in the scintillator. A total 2,679,807 cpm was added to each experimental unit (Table 1). As can be seen in Table 1, the destination of most of the radioactivity used in each experimental unit was determined.

$\mathrm{SE}$ is a complex process that involves multiple factors, including the biosynthesis of IAA through the TAA/YUC pathway [35]. To test whether the CCYUC genes were participating during the SE induction process in C. canephora, we performed a quantitative expression analysis of CcYUC transcript levels. First, we determined how many $Y U C$ genes were in the genome of $C$. canephora (http://coffee-genome.org/ [36]). The search yielded eight YUC genes. Two copies of the CcYUC1 gene and two copies of the $C c Y U C 10$ gene were found throughout the genome. At the same time, we performed an analysis of the transcriptome of $C$. canephora [37]. The results showed the presence of five transcripts of CCYUC gene products during the induction of SE. Two of these five transcripts belonged to the CCYUC1. The locus of the CCYUC1 gene is on Chromosome six in the genome of C. canephora, and structurally consists of five exons and four introns with a length of 3060 base pairs (Figure 4A). The reading frame of the CCYUC1 gene predicted a 519 amino acid protein of $59 \mathrm{kDa}$ molecular mass, with FAD motifs (Figure 4B) characteristic of flavin monooxygenase enzymes. To gather a complete picture of the participation of the CcYUC family during the induction of SE, we analyzed the expression of seven CcYUC genes, including the two copies of the CcYUC1 gene, CcYUC3, CcYUC4, CcYUC6, and CcYUC10 genes and one CcYUC-like gene (Supplementary Table S1). 
A

CcYUC1 gene

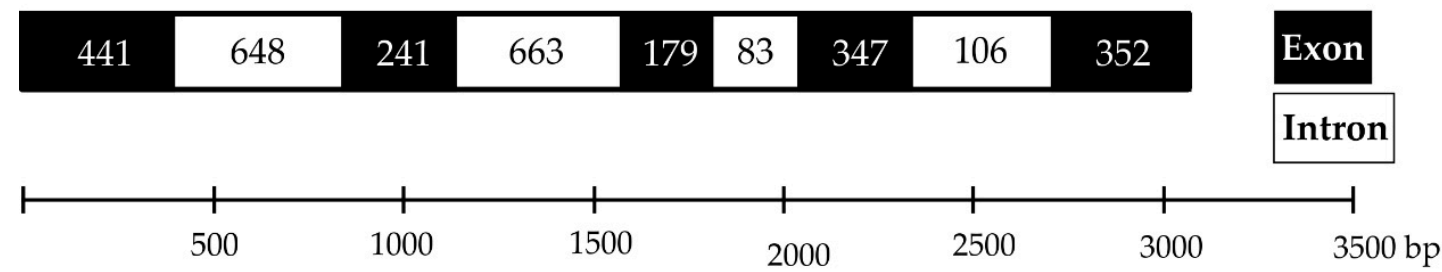

B

CcYUC1 nucleotide sequence

MAIFSKIGIVGAGISGIAAAKQLRKYDPIIFEATDSLGGVWKHCSYRSTKLQTPRCDYEFSDFPWTQR DNSSFPTHLEVLEYLHSYATHFGVVELIKFSSKVVEIRFVGNHANDPDDQVNSNGYGNLLNGQPV WEVAVQTSESDTVEWYAFELLVICTGKYGDVPIIPQFPHNKGPEVFKGQVLHSLDYCKLDEENSVQL LKDKKVVVVGYKKSAIDLAVECAKANQGPDGQPCTIVVRTLHWTIPHYSIWGLPFYLFYSTRASQF LHERPNQGILRNIFCKLLSPVRNAMSKIIESYLVWRLPLEKYGLKPDHPFVEDYGSCQMAILPEELFE EAEKGMIDFKKASKWCFWEGGVEFDDNTKLEADVVLLATGFDGKRKLRNILPEPFRSLLETEGMM PLYRGTIHPLIPNMAFVGYIESVSNLHTAEIRCKWLSRLADNYFKLPSVGQMLEQTQKEMGIMRKTT RFYKRSCISTFSINHTDEICEEMGWKSWRKNNWLAEAFSPYCSQDYQEQKHID

519 aa $59 \mathrm{kDa}$

Figure 4. Gene structure and protein sequence of YUC1 in C. canephora. (A), The length of the YUC1 gene is 3060 base pairs, and the structure consists of five exons and four introns. (B), The YUC1 gene coding sequence produces a 519 amino acid protein with a molecular mass of $59 \mathrm{kDa}$. Bold letters indicate the FAD binding motif.

The analysis of the CCYUC expression was performed by qRT-PCR for samples taken on the $-14,0,7,14,21$, and 28 dai of SE. Among the CcYUC genes analyzed, it was found that the CcYUC1 gene was especially highly expressed, and its transcription level showed a distinguishably substantial increase on the zero days of SE induction (up to 6.8-fold) (Figure 5A). On Days 7, 14, and 21 of SE, the transcriptional activity of CcYUC1 decreased but then had a slight increase on Day 28 (up to 1.2-fold). In contrast, CcYUC1-putative was only expressed on Day 0 (Figure 5B), and CcYUC4 had two expression peaks, on Day 0 (up to 4.2-fold) and at 28 dai (up to 2.7-fold), respectively (Figure 5C). CcYUC3 (Figure 5D) and CcYUC6 (Figure 5E) genes showed low levels of transcripts compared to Day -14 throughout the entire SE induction process. CCYUC10 had very similar expression times 7 and 21 dai of SE (Figure 5F). The CcYUC-like gene was expressed only during the pre-treatment stage, with a 3-fold increase at the end of the pre-treatment and just before the explants were introduced into the induction medium (Figure 5G). Once in the explant was in the presence of the induction medium, the expression of the CcYUC-like gene disappeared. Of the seven analyzed CcYUC genes, four genes, including CcYUC1, CcYUC1-putative, CcYUC4, and CcYUC-like, were upregulated on Day 0, while CcYUC3 and CcYUC6 were downregulated during the SE induction process. The behavior of CcYUC10 did not follow a definite pattern along with the stages of induction of SE. 

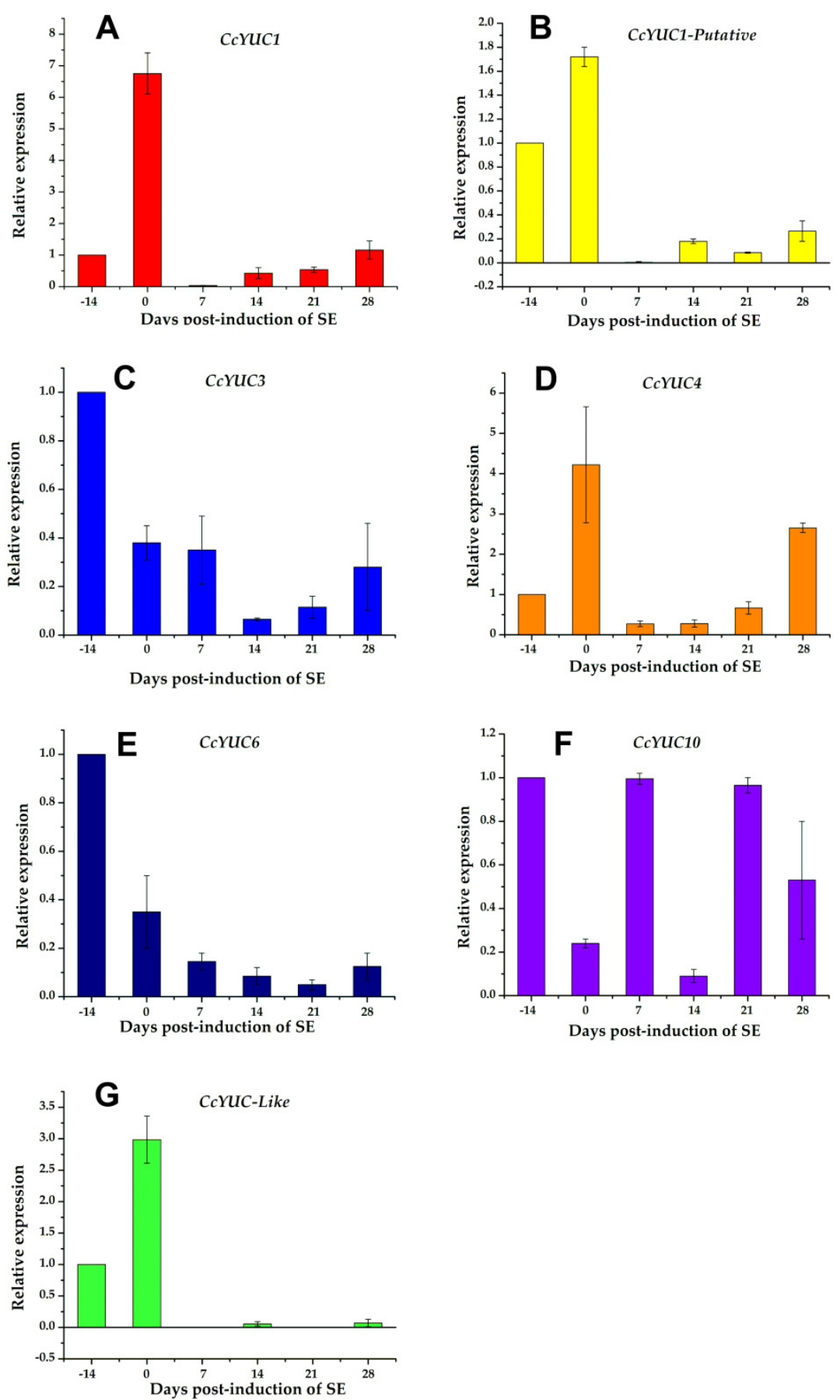

Figure 5. Expression levels of individual CcYUC genes during the induction of SE in C. canephora. (A), CcYUC1; (B), CcYUC1-putative; (C), CcYUC3; (D), CcYUC4; (E), CcYUC6; (F), CcYUC10 and (G) CcYUC-like. Actin was used as an internal qRT-PCR reference. The bars over the columns represent the mean value \pm standard error of three independent experiments.

\subsection{Endogenous Free IAA Accumulation and Localization during the SE Induction Process}

To investigate whether there was a specific localization of IAA in leaf explants of C. canephora during the process of SE induction, we used an anti-IAA mouse monoclonal primary antibody specific for free IAA and an Alexa Fluor 488-labeled anti-mouse IgG expand secondary antibody.

Previously, it was reported that auxin response gradients were established in specific regions of the embryonic callus and were responsible for SE $[38,39]$. 
Cross-sections of leaf tissue, $30 \mu \mathrm{M}$ thick, were made of explants of $C$. canephora leaf during the process of induction of SE. After pre-treatment, we observed the cells that were part of the tissue structure. This tissue was made of spongy and palisade mesophyll cells (Figure 6A,G). In addition, although no morphological change was observed between the control explants and those treated with $100 \mu \mathrm{M}$ yucasin, there was a difference in the thickness of the explant. In tissues treated with $100 \mu \mathrm{M}$ yucasin, it was observed that the thickness of the tissue was thinner compared to the control (Figure 6A,G). It is possible that the yucasin inhibitor caused this effect.
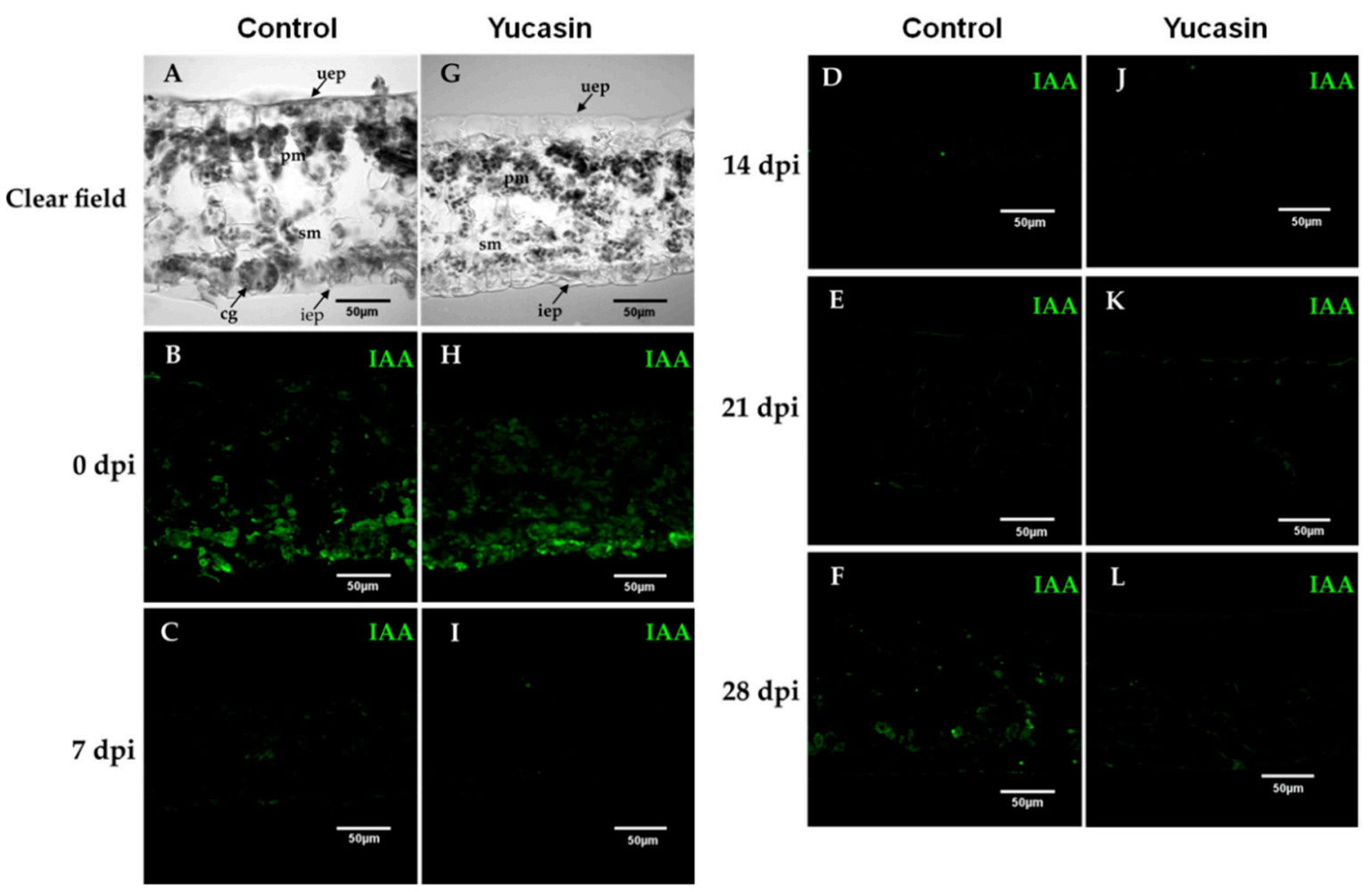

Figure 6. Free IAA immunolocalization during the SE induction process in C. canephora. Confocal images of longitudinal sections of leaf explants $0,7,14,21$, and 28 dai of SE without (A-F), and with yucasin $(\mathbf{G}-\mathbf{L})$. (A,G), Transmitted light differential interference images of a longitudinal sections of leaves during the induction of SE. (B,H), (0 days); (C,I), (7 dai); (D,J), (14 dai); (E,K), (21 dai); (F,L), (28 dai). IAA was visualized with the Alexa 488 chromophore bonded to the antibody that recognizes the antibody-IAA (green). Upper epidermis: uep; lower epidermis: iep; spongy mesophyll: sm; palisade mesophyll: pm.

In our study, on Day 0, we found a strong free IAA signal during the SE induction process (Figure 6B). The signal decreased from 7 dai (Figure 6C) through 14 dai (Figure 6D). At 21 dai (Figure 6E), the IAA signal began to increase. Seven days later, the increase of the IAA signal was much more significant (Figure 6E), and was localized at the edges of the explants and in the cell walls of the spongy mesophyll cells (Figure 6E).

On the other hand, the immunolocalization assays of free IAA of the yucasin-treated samples revealed important changes in the IAA signal accumulation pattern. At Day 0 of the SE induction process, we found a free IAA auxin signal in explants treated with $100 \mu \mathrm{M}$ yucasin (Figure $6 \mathrm{H}$ ). The free IAA signal found was less intense than in the control samples (Figure 6B). The IAA signal disappeared from Day 7 to Day 21 after the induction of SE (Figure 6I-K). An essential difference from the control samples was the decrease in the IAA signal, in the presence of the yucasin, at 28 dai (Figure 6L) compared with the control at the same stage (Figure 6F). 
The next step was to determine, intracellularly, the location of the IAA signal (Figure 7). The endogenous accumulation of free IAA was located in the interior chloroplasts and nucleoplasm of spongy mesophyll cells (Figure 7B).
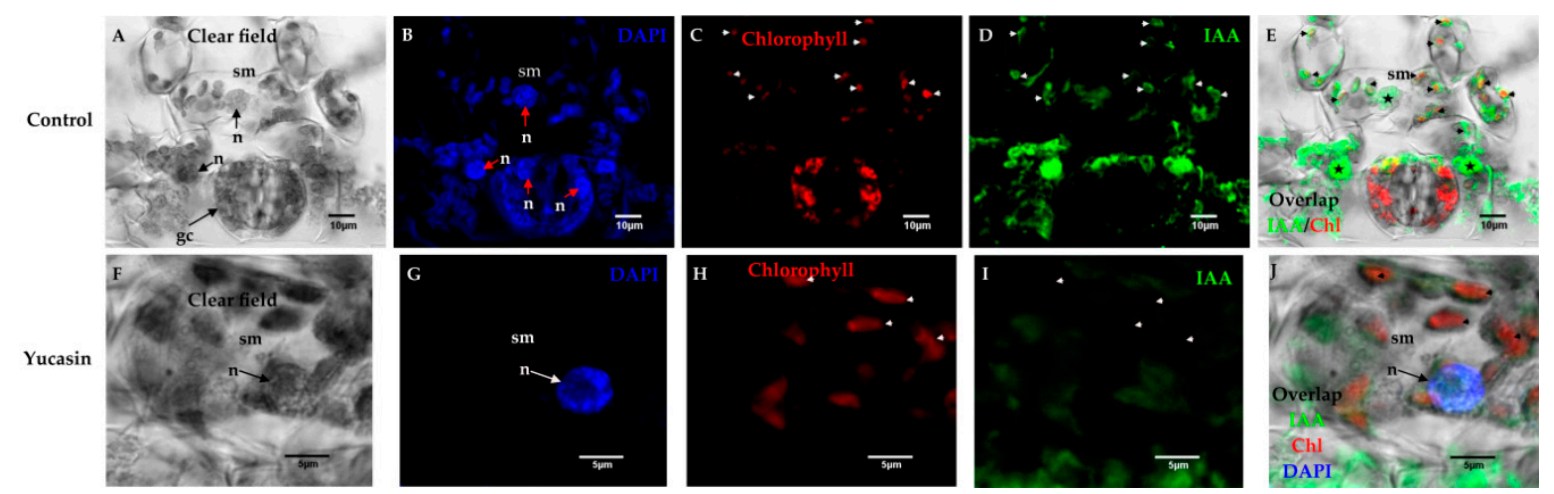

Figure 7. Free IAA immunolocalization on Day 0 of the SE induction process in C. canephora. Confocal microscopy images of cross-sections of leaf explants 0 dai of SE. (A), clear field; (B), nuclei staining with blue DAPI; (C), red chlorophyll signal; (D), free IAA signal in green; and (E) overlapping of the free IAA and chlorophyll signals. Note that there was IAA in the chloroplasts (short white arrows) and nucleoplasm (bold stars) of the spongy mesophyll (sm) cells; (F), light field; (G), nuclei staining with DAPI in blue; $(\mathbf{H})$, chlorophyll signal in red; (I), free IAA signal in green color; (J), overlapping of IAA signal, chlorophyll, and DAPI on Day 0 of SE induction. IAA was not in the chloroplasts or the nucleoplasm of the spongy mesophyll cells, but in the cytosol. Mesophyll cells: sm; nucleus: $n$.

In control tissues, numerous chloroplasts were located within the spongy mesophyll cells (Figure 7A). These cells had prominent nuclei (Figure 7B). The free IAA signal was found both in the chloroplasts and in the nuclei of the spongy mesophyll cells (Figure 7E). We showed that IAA free of mouse anti-IAA monoclonal primary antibodies was specific (Figure 7D) and the signal was not mixed with chlorophyll (Figure 7C). In treatments with $100 \mu \mathrm{M}$ of yucasin, the free IAA signal was found in the cytosol (Figure 7I) and not in the chloroplasts or nuclei (Figure 7G-J), as in the control.

\subsection{Effect of the Inhibition of Auxin IAA Biosynthesis by Yucasin during the SE Induction Process in C. canephora}

Several studies have shown that the pathway of IAA biosynthesis in most plants occurs through two simple steps from tryptophan, mediated by TAA and YUCs $[19,20,40]$. The tryptophan-dependent pathway for IAA biosynthesis through YUC genes could be a determining factor for the development of embryogenesis [15]. At the same time, different groups have shown that an increase in the amount of IAA is required to initiate the induction of SE [41,42]. Our results (Figure 3) showed an increase in the IAA content during the pre-treatment phase. To test whether CcYUC-mediated IAA biosynthesis was required for the SE induction process, we used the auxin biosynthesis inhibitor, yucasin, which specifically inhibits the function of YUC proteins [28].

The results showed that the efficiency in the formation of proembryogenic mass was severely affected by the treatment in a dose-dependent way (Figure 8A). Twenty-one dai, the explants treated with the inhibitor showed a decrease in proembryogenic mass formation, particularly at 20, 50, and $100 \mu \mathrm{M}$ of yucasin (Figure 8A). After 56 days of SE, all of the explants from plants incubated in the presence of yucasin during pre-treatment showed signs of damage, including tissue necrotization and phenolization (Figure $8 \mathrm{~A}$ ). The treatments with 50 and $100 \mu \mathrm{M}$ of yucasin completely inhibited the development of the proembryogenic mass from 28 dai on (Figure 8B). 


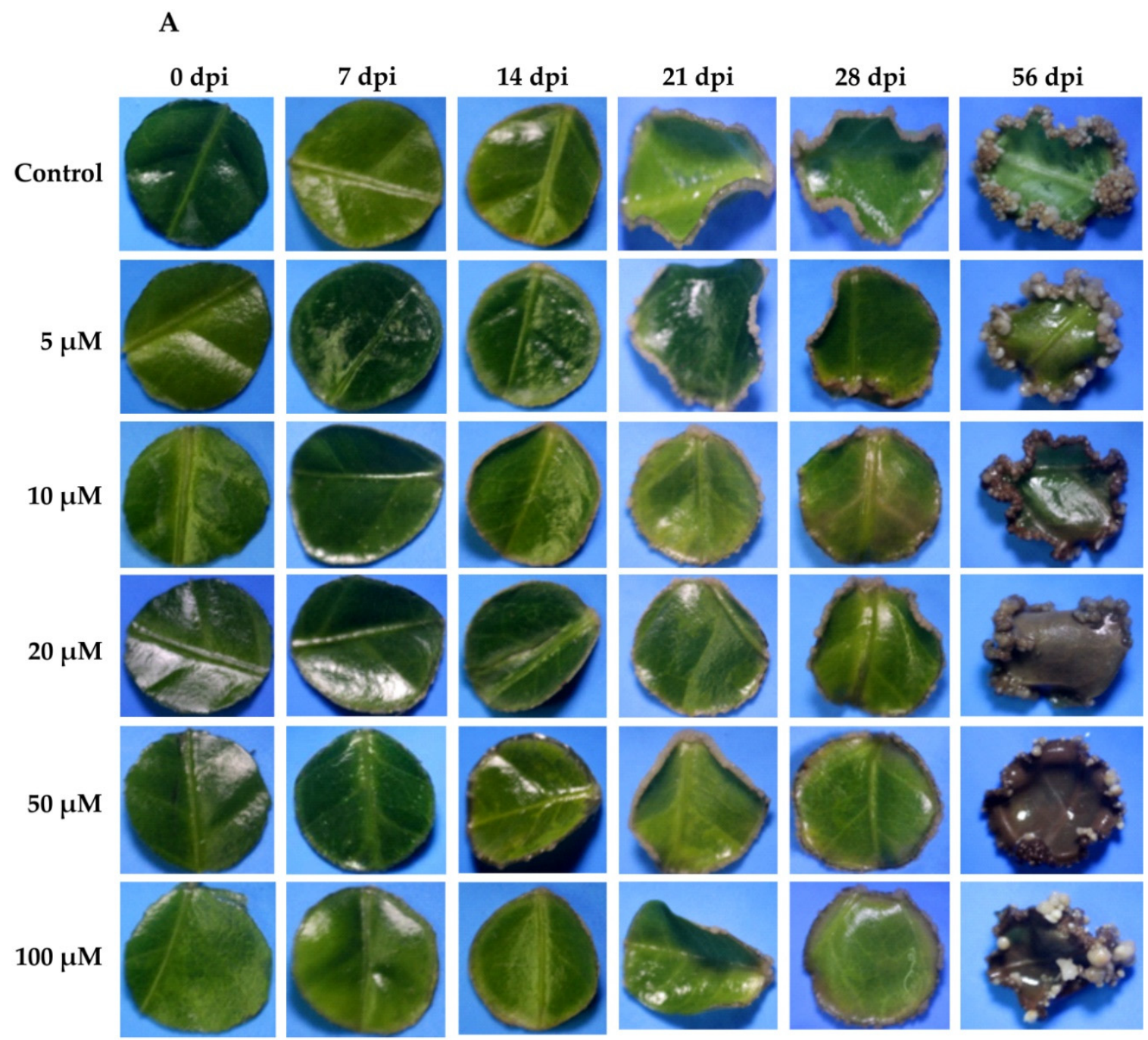

B

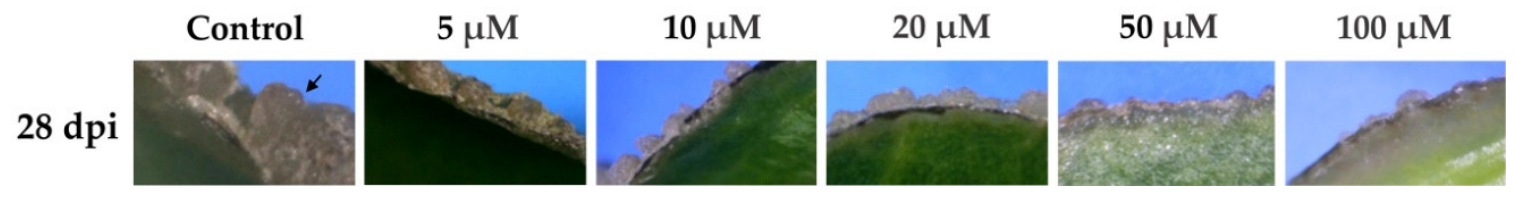

Figure 8. Effect of yucasin during the induction of SE in C. canephora. (A), Different concentrations of yucasin were applied exogenously $(5,10,20,50$, and $100 \mu \mathrm{M})$ to the pre-treatment medium. The effect of yucasin was documented every seven days until 28 dai, and then at 56 dai of SE. (B), A comparison of the effect of yucasin 28 dai for all the yucasin concentrations. Note the abundance of proembryogenic mass on the control, as well as the presence of proembryos (black arrow).

The presence of free IAA decreased significantly after the explants were transferred to the SE induction medium (Figure 3). However, this small amount of IAA was very important for the induction of the embryogenic process. When yucasin was added, this small amount disappeared and the embryogenic process did not take place (Figure 9). 


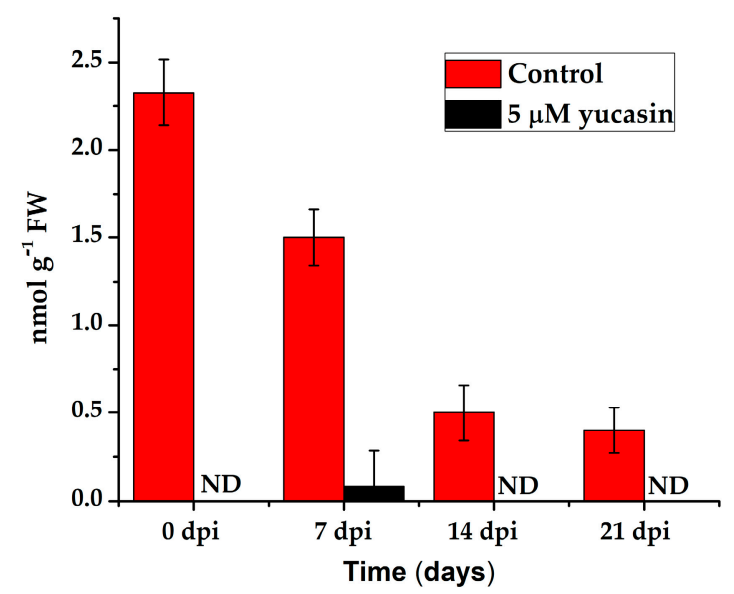

Figure 9. Quantification of the IAA endogenous content in leaf explants of C. canephora treated with $5 \mu \mathrm{M}$ yucasin. Samples were collected at $0,7,14$, and 21 days after SE induction. The bars over the columns represent the mean value \pm standard error of three independent experiments. ND: not detected.

Quantification of the number of embryos produced 56 dai showed a significant decrease in the number of embryos produced by the explants exposed to the yucasin inhibitor (Figure 10). In the presence of the inhibitor, only globular-shape embryos were formed. The decrease varied from 72 to $94 \%$ of the control. Even the lower concentration of the inhibitor produced a sharp decrease in the number of embryos. In the presence of $10 \mu \mathrm{M}-100 \mu \mathrm{M}$ of yucasin, the number of globular embryos was less than 40 embryos per flask, in comparison with 300 globular embryos per flask for the control.

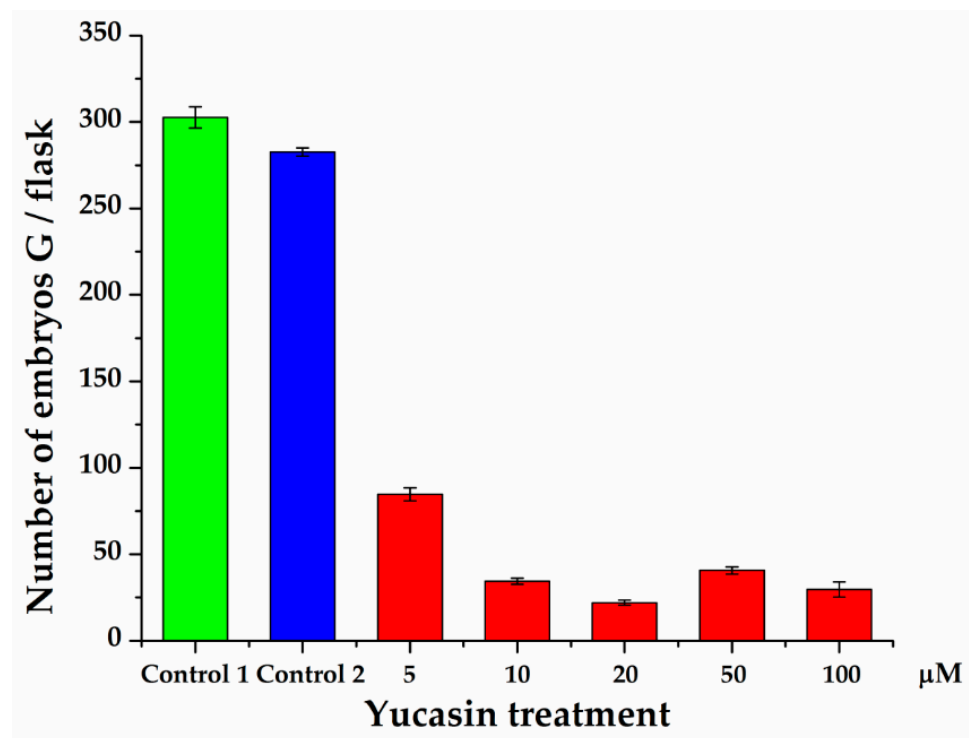

Figure 10. Effect of yucasin on the production of somatic embryos during the induction process in C. canephora. Control 1 is the treatment without any addition to the induction medium. In Control 2, DMSO was added to the semisolid pre-treatment medium. Only globular-stage embryos were formed after 56 days, so the comparison was limited to the number of globular embryos formed throughout SE induction. The data are the results of three independent biological experiments; the bars represent the standard error.

\subsection{Restoration of Somatic Embryogenesis by Exogenous Addition of IAA}

To confirm that the effect seen on somatic embryo production was due to the inhibition of IAA biosynthesis as a result of yucasin treatment, we added $1.0 \mu \mathrm{M}$ of IAA to the medium of induction of the SE containing the explants treated previously with $100 \mu \mathrm{M}$ yucasin-induction medium. Twenty-eight days after the exogenous addition of IAA, the embryogenic process inhibited by the yucasin was 
restored (Figure 11A). It was possible to see all of the stages of development after the addition of exogenous IAA (Figure 11B,C). In contrast, the samples treated with yucasin but not exogenous IAA did not produce embryos, beyond the few globular embryos already present at the beginning of the experiment (Figure 11D,E). The somatic embryos produced after the addition of the exogenous IAA were entirely normal, and the somatic embryos reached the cotyledonary stage (Figure 11F). The production of somatic embryos in the induction medium containing yucasin + exogenous IAA was more than $77 \%$ higher than in the control without yucasin (Figure 11G).
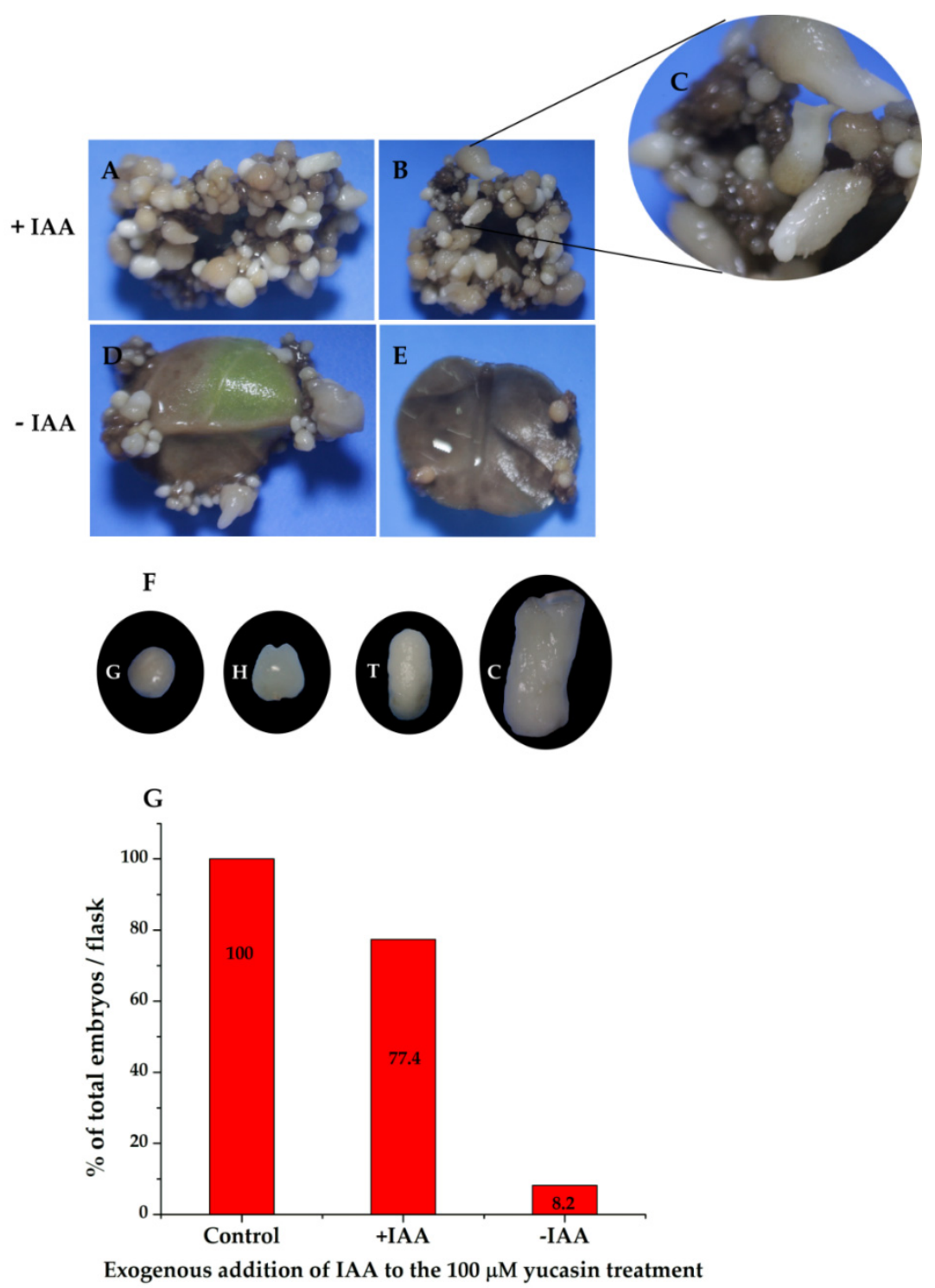

Figure 11. The exogenous addition of IAA restored somatic embryogenesis in explants previously treated with $100 \mu \mathrm{M}$ yucasin. (A,B), Restoration of somatic embryogenesis by exogenous application of IAA to explants treated with $100 \mu \mathrm{M}$ yucasin. (C), Close-up shows the presence of somatic embryos at different stages of development. (D,E), Explants in the presence of $100 \mu \mathrm{M}$ yucasin. (F), Different development stages of somatic embryos after four weeks in the presence of exogenous IAA. (G), The total percentage of embryos formed in flasks with and without IAA.

\section{Discussion}

Several biochemical and genetic studies of SE have been reported, involving A. thaliana [43], Brassica napus [44], Medicago truncatula [45], Coffea spp. [2,46], and many other species [4,47,48]. 
However, the mechanism by which somatic cells change their genetic program and become somatic embryos is not yet fully understood.

$\mathrm{SE}$ is a complex process and is strictly regulated. In this work, we focused on IAA biosynthesis mediated by YUCs. It has been reported that auxin transport $[17,49]$ and signaling plays an essential role throughout the entire life cycle of plants, including embryogenesis [16,50-52].

In this study, we showed that CCYUC-mediated IAA biosynthesis is required during the SE induction process in C. canephora. Histological analysis showed that at the beginning of the proliferation of the proembryogenic mass 21 dai, the embryogenic cells appeared near the vascular tissue (Figure 2D). The formation of embryogenic structures was observed from 28 dai onwards. By 56 dai, all of the different development stages of the somatic embryos of $C$. canephora were present (Figure 1). These data were in line with the well-documented fact that mesophyll cells located near vascular bundles of leaves are the first to divide $[53,54]$. These cells produce up to fivefold more proteins than non-embryogenic cells [55]. The embryogenic cells are characterized as small, isodiametric, and densely cytoplasmic. These cells then undergo a series of successive divisions to give rise to a somatic embryo [11].

The increase in the level of IAA during the pre-treatment period [41] (Figure 3) could have been due to de novo biosynthesis. The increases in the expression of CcYUC1, CcYUC1-putative, CcYUC4, and CcYUC-like during the pre-treatment supported this assumption (Figure 5). Consistent with this hypothesis, qRT-PCR expression analysis of the CcYUC genes during the SE induction process showed that most (5/8) of the CCYUC genes encoded in the genome were transcriptionally active at the beginning of the SE induction. The transcription levels on Day 0 were congruent with the free IAA signal found in the explants in the induction medium. The YUC gene family encodes flavin monooxygenase enzymes for the biosynthesis of IAA from IPA [20]. Biochemical and genetic studies indicate that plants use Trp as a substrate, which is converted to IPA as an intermediary for the production of IAA [21]. The use of $3-{ }^{14} \mathrm{C}$-Trp permitted us to confirm that the increase in the IAA content came from de novo biosynthesis (Table 1).

In situ hybridization has determined YUC1 and YUC4 expression at the apical meristem and primordia of young leaves during organogenesis in $A$. thaliana $[26,56,57]$. These genes are activated quickly after wounding (within $4 \mathrm{~h}$ ), suggesting that these two genes participate in the production of endogenous auxin in leaf explants [57]. In this same model, the overexpression of $Y U C$ genes increased the endogenous content of IAA in young leaves. The mutation of the YUC genes produced a drastic decrease in the content of IAA [21,58,59]. Similarly, in maize, YUC mutations have been shown to cause a reduction of IAA levels and disturb the vegetative development [60].

In A. thaliana, the inhibition of YUC genes prevents the expression of WOX11, resulting in the blocking of rooting [57]. This labor is divided among the different YUC genes. YUC1 and YUC4 are expressed suddenly in response to wounding after detachment in both light and dark conditions and promote auxin biogenesis in both mesophyll and competent cells [57]. These two genes are also expressed at the beginning of the induction of the SE in C. canephora (Figure 5), suggesting a similar role in both species. However, the inactivation of a single YUC gene does not cause developmental defects, due to the redundant function between YUC genes in A. thaliana $[24,26]$. Therefore, we used a specific inhibitor to block the function of YUC enzymes in C. canephora. Yucasin inhibits the activity of YUC enzymes and suppresses the effect of the high-auxin phenotype of YUC overexpression found in $A$. thaliana [14]. The results shown in Figure 8 revealed that the inhibition of IAA biosynthesis (Figure 9) strongly affected the progress of SE in C. canephora. The immunolocalization of IAA in C. canephora explants treated with the inhibitor (Supplementary Figure S6) shows no signal in the explants exposed to yucasin (Supplementary Figure S6C or Figure S6G).

The exogenous addition of IAA to explants treated with yucasin restored the SE process (Figure 10). These results revealed that the YUC-mediated biosynthesis of the auxin IAA is critical for SE in C. canephora. The IPA pathway is highly conserved in land plants; however, since IAA can be synthesized through five different routes, one of them independent of tryptophan (from 
indole-3-glycerol phosphate $[61,62])$, a contribution to the IAA pool from some combination of the other four routes cannot be rule out.

In this study, we used different concentrations of yucasin $(5,10,20,50$, and $100 \mu \mathrm{M})$. We showed that yucasin inhibited the production of somatic embryos in explants of $C$. canephora (Figure 10). The action of IAA occurs in its free form and acts in the nucleus on the expression of auxin-response genes [63]. Different concentrations of this auxin may give rise to various physiological processes [64]. Its synthesis and distribution in tissue determine the action of auxin, mainly via its polar transport during SE in A. thaliana [17,65]. During zygotic embryogenesis, IAA is regulated by its biosynthesis and spatiotemporal localization through specific carriers of auxin PIN (pin-formed) and ABCB (ATP-binding cassette protein subfamily B) [66-68].

On the other hand, the IAA found in treatments with $100 \mu \mathrm{M}$ yucasin was possibly due to two factors: first, the release of IAA through hydrolysis of IAA conjugates. Conjugation plays a central role in the homeostasis of IAA [58,69], and this reaction is catalyzed by the Gretchen Hagen 3 enzymes (GH3) family of acyl acid-amido synthetases [70]. The IAA found in this work in explants with yucasin could have been the result of IAA-Leu-resistant (IRL) enzyme activity. In the absence of de novo biosynthesis of IAA (by the inhibition of yucasin), the IAA conjugates hydrolyze to leave it in its free form [71]. IAA metabolism depends on which amino acid is attached; for example, the conjugation of IAA with alanine or leucine results in a form that is stored but can be easily hydrolyzed [72]. Auxin conjugates are hydrolyzed to release IAA to maintain intracellular homeostasis in tissues in response to environmental conditions [73]. Recently, hydrolysis of aspartic (IAA-asp) and glutamic (IAA-glu) conjugates was reported in strawberry plants to provide free IAA for fruit growth [74]. The second factor that could explain the presence of IAA in explants treated with yucasin is the existence of an alternate route to produce IAA [58]. Indole-3-acetaldehyde (IAAld) has been proposed as an intermediary in the IAA biosynthesis pathway, since some bacteria produce IAA from IPA using IAAld as an intermediary [75]. However, there is not enough evidence for this theory. Therefore, IAAld is unlikely to participate in the IPA pathway [21]. Another auxiliary route in the biosynthesis of IAA is from indole-3-acetaldoxime (IAOX) [31]. CYP79B2 and CYP79B3 catalyze the conversion of Trp to IAOx [76]. However, it has been reported that the IAOx pathway is specific to Brassicaceae plants, because CYP79B genes are very limited in these species [31].

However, many questions remain unanswered about the de novo biosynthesis of IAA during the SE induction process. Several factors are implicated in its induction, including alteration of the cell wall composition, changes in growth regulators, genetic expression, and epigenetic regulations [12]. Furthermore, although it is believed that the predominant route in auxin synthesis is from IPA, the molecular mechanisms that regulate biosynthesis at the transcriptional level and protein level are unknown [77].

In summary, the data in this research suggest that the pre-treatment of the coffee plantlets produced an increase in the level of IAA. This increase was due to de novo biosynthesis, and the presence of IAA at the beginning of the induction of SE in C. canaphora is indispensable for the process to begin.

\section{Materials and Methods}

\subsection{Plant Material and Growth Conditions}

C. canephora plantlets were propagated and maintained under in vitro photoperiod conditions $16 / 8 \mathrm{~h}\left(150 \mu \mathrm{mol} \mathrm{m}{ }^{-2} \mathrm{~s}^{-1}\right)$ at $25 \pm 2{ }^{\circ} \mathrm{C}$ in MS inorganic culture medium ([78], PhytoTechnology Laboratories, M524, Shawnee Mission, KS, USA). The MS medium contained $29.6 \mu \mathrm{M}$ thiamine-HCl (Sigma, T3902, St. Louis, MO, USA), $550 \mu \mathrm{M}$ myo-inositol (Sigma, I5125, St. Louis, MO, USA), $0.15 \mu \mathrm{M}$ L-cysteine hydrochloride hydrate (Sigma, C8277, St. Louis, MO, USA), $16.24 \mu \mathrm{M}$ nicotinic acid (Sigma, N4126, St. Louis, MO, USA), $87.64 \mathrm{mM}$ sucrose, and 0.25\% (w/v) CultureGel TM Type I-Bio Tech Grade (PhytoTechnology Laboratories, G434, Shawnee Mission, KS, USA), pH 5.8. Plantlets were subcultured every 6 weeks by in vitro transplantation of shoot intermodal segments to fresh maintenance media. 


\subsection{Induction of Somatic Embryogenesis in C. canephora}

For the induction of SE, we started with 4 month old plantlets of C. canephora cultured under in vitro conditions. A batch of plantlets was selected and placed in semisolid medium for pre-treatment. The culture medium was MS medium, supplemented with $0.54 \mu \mathrm{M}$ NAA (Sigma N1145, St. Louis, MO, USA) and $2.32 \mu \mathrm{M}$ Kin (Sigma K0753, St. Louis, MO, USA), for fourteen days under photoperiod conditions ( $16 \mathrm{~h}$ light $/ 8 \mathrm{~h}$ dark) at $25 \pm 2{ }^{\circ} \mathrm{C}$. For the induction of SE, Leaves two and three were used. The explants were cut into circles of approximately $0.25 \mathrm{~cm}$ in diameter and transferred to Yasuda liquid medium [79] supplemented with $5 \mu \mathrm{M}$ BA (PhytoTechnology Laboratories, B800, Shawnee Mission, KS, USA). The cultures were incubated in the dark at $25 \pm 2{ }^{\circ} \mathrm{C}$ with shaking (100 rpm) for 56 days [80]. Samples were taken $0,7,14,21$, and 28 days after induction (dai) of SE.

\subsection{Extraction of Auxins and Their Conjugates}

For the extraction of auxins and their conjugates, $100 \mathrm{mg}$ of tissue was used from Days-14, -9, and -4 of pre-treatment; on Day 0 of the induction of SE and 0.02, 0.04, 1, 7, 14, and 21 days after the induction of SE. The samples were stored at $-81^{\circ} \mathrm{C}$ until use. The frozen tissue was ground with liquid nitrogen and mixed with $1 \mathrm{~mL}$ of acidic water (the $\mathrm{pH}$ was adjusted to 2.8 with $\mathrm{HCl}$ ). The mixture was transferred to a test tube with an additional milliliter of acidic water. The mixture was stirred for $1 \mathrm{~min}$ with $1 \mathrm{~mL}$ of a solution of butylated hydroxytoluene (Acros Organics, 112992500, Thermo Fisher Scientific, NJ, USA), and then $1 \mathrm{~mL}$ of ethyl acetate (CTR Scientific 00184, Monterrey, Mexico) was added. The mixture was stirred for $1 \mathrm{~min}$ and the supernatant recovered. Next, $2 \mathrm{~mL}$ of ethyl acetate was added, stirred for $1 \mathrm{~min}$, and the supernatant was recovered. This operation was repeated once more. From this mixture, $3 \mathrm{~mL}$ of the organic phase was taken and evaporated with nitrogen gas. The dried sample was resuspended in $1 \mathrm{~mL}$ of the mobile phase, filtered through a Millipore filter $(0.22 \mu \mathrm{M})$ and analyzed using high-resolution liquid chromatography (HPLC) (60\% acetonitrile; JT Baker 9017-03 (Thermo Fisher Scientific, NJ, USA): 40\% water containing 0.5\% (v/v) acetic acid; CTR Scientific, 00500, Monterrey, Mexico). The standards used were IAA (Sigma, I1250, St. Louis, MO, USA) and IAA-Ala (Sigma, 345911, St. Louis, MO, USA). Preparation of IAA-Glu, IAA-Leu, and IAA-Asp was previously reported [41].

\subsection{High-Performance Liquid Chromatography}

For the analysis of the samples, an Agilent Technologies 1200 high-resolution liquid chromatograph (HPLC) consisting of a quaternary array of pumps (Agilent Technologies G1311A, Santa Clara, CA, USA) connected to an automatic injector (Agilent Technologies G1329A, Santa Clara, CA, USA) was used. A total $20 \mu \mathrm{L}$ of the tissue extract was injected and subjected to chromatography with an isocratic elution system with a flow rate of $0.6 \mathrm{~mL} \mathrm{~min}^{-1}$ in a $C_{18}$ reverse-phase column (Phenomenex, Torrance, CA, USA) of $250 \mathrm{~mm} \times 4.6 \mathrm{~mm}$. The samples were analyzed with a fluorescence detector (Agilent Technologies G1321A, Santa Clara, CA, USA) at an emission length of $280 \mathrm{~nm}$ and an excitation length of $340 \mathrm{~nm}$. The presence of compounds in the analyzed samples was determined by the retention times of IAA and of IAA-Ala, IAA-Leu, IAA-Glu, and IAA-Asp conjugates (Supplementary Figures S1-S3), for which co-injections of the standards and the samples were analyzed, to determine whether they co-eluted. The calibration curves were made with free IAA and the conjugate standards using the area under each curve for each compound.

\subsection{Liquid Chromatography-Mass Spectrometry of Auxins}

LC-MS/MS analysis was performed using a Thermo LTQ Orbitrap (Thermo Fisher, Carlsbad, CA, USA), equipped with a heated-electrospray ionization (HESI-II) source with sheath gas set to 60 , auxiliary gas set to 20 , source temperature set to $310^{\circ} \mathrm{C}$, and spray voltage $4 \mathrm{kV}$ in a positive mode. To determine the chemical fragmentation of auxins, a solution of an individual auxin at a concentration of $100 \mu \mathrm{g} \mathrm{mL} \mathrm{mL}^{-1}$ in methanol:water $(80: 20 ; v / v)$ was directly infused on LTQ Orbitrap 
at $5 \mu \mathrm{L} \mathrm{min}{ }^{-1}$. The collision energy dissociation (CID) parameter for auxins was optimized to yield either parent-ion-dependent product ions $(\mathrm{M}+\mathrm{H})^{+}$and nearly $20 \%$ of the parent ion. Chromatographic separations were performed using a reverse-phase ZORBAX Eclipse XDB $C_{18}(150 \times 4.6 \mathrm{~mm}$ i.d., $5 \mu \mathrm{m}$ particle size, $80 \AA$ A pore size) column (Agilent Technologies, G1321A). A gradient of $0.1 \%$ formic acid in water (Solvent A) and $0.1 \%$ formic acid in acetonitrile (Solvent $\mathrm{B}$ ) was used during LC separations. A flow rate of $0.3 \mathrm{~mL} \mathrm{~min}^{-1}$ was used, and the injection volume was $2 \mu \mathrm{L}$. The gradient program was $5 \% \mathrm{~B}$ at $0 \mathrm{~min}$, to $20 \% \mathrm{~B}$ at $20 \mathrm{~min}$, to $30 \%$ at $32 \mathrm{~min}$, to $80 \%$ at $34 \mathrm{~min}$, to $100 \%$ at $36 \mathrm{~min}$, kept at $100 \%$ for $2 \mathrm{~min}$, and then to $5 \%$ at $40 \mathrm{~min}$ and kept at $5 \%$ for $6 \mathrm{~min}$. Retention time and spectra were processed with raw Xcalibur data files.

\subsection{Preparation of Seedlings in the Presence of $3{ }^{14} \mathrm{C}-\mathrm{Tr} p$}

Seedlings were incubated in the presence of $3-{ }^{14} \mathrm{C}-\operatorname{Trp}$ (NEN-Dupond; $1.85 \mathrm{MBq} 55 \mathrm{mC} \mathrm{mmol}{ }^{-1}$ ) during the 14 days of pre-treatment in MS liquid medium supplemented with NAA $0.54 \mu \mathrm{M}$ and Kin $2.32 \mu \mathrm{M}$. Auxins were isolated on Days $-14,-9,-7,-4$, and 0 of pre-conditioning. To monitor the incorporation of labeled Trp into the IAA, the auxinic extract was run on a silica TLC plate with an alumina fluorescent indicator Kieselgel 60 F254 (Merck, 105554, CDMX, Mexico). Five microliters of the leaf extract incubated with $3-{ }^{14} \mathrm{C}$-Trp and $5 \mu \mathrm{L}$ of the Trp standards $(0.25 \mu \mathrm{L}$; Sigma, T0254, St. Louis, MO, USA), indol-3-pyruvic acid (IPA, $1 \mu \mathrm{L}$; Sigma, L7017, St. Louis, MO, USA) and IAA $(0.25 \mu \mathrm{L}$; Sigma 45533, St. Louis, MO, USA) was applied to the plates. The samples were run for $3 \mathrm{~cm}$ using a mixture of chloroform:ethyl acetate (50:50) as the mobile phase, and Salkowski reagent was used as a developer. Bands were identified by the $R_{f}$ of the compounds. The silica of each band was scraped, deposited in vials with scintillation liquid, and the radioactivity of each was quantified in a scintillation counter (Beckman 6500, CDMX, Mexico).

To track the destiny of the all of the radioactivity used, we used the following protocol. Once the auxins were extracted from pre-treatment seedlings that were incubated in the presence of $3-{ }^{14} \mathrm{C}$-Trp, $5 \mu \mathrm{L}$ of the total $100 \mu \mathrm{L}$ of the leaf extract was placed on a chromatographic plate, as well as Trp, IPA, and IAA standards. The spots were developed with the Salkowski reagent (stain compounds containing an indole group). Each spot on the plate was associated with the corresponding standards. Each spot was scraped off the plate and placed in a scintillation vial to count the radioactivity present. In order to be certain that there were no radioactive compounds outside those marked by the developer, the areas between the spots were cut, and the radioactivity was determined. No radioactive label was detected in any case.

\subsection{Yucasin Inhibition Assay}

Yucasin, an inhibitor of the YUC protein function in the auxin biogenesis pathway (5-(4-chlorophenyl)-4H-1, 2, 4-triazole-3-thiol (Santa Cruz Biotechnology, 233161, Santa Cruz, CA, USA)), was added to the pre-treatment semisolid medium at concentrations of 5, 10, 20, 50, and $100 \mu \mathrm{M}$ for fourteen days under dark conditions. Leaf explants of C. canephora plantlets treated with yucasin were transferred to the SE induction medium [5]. Yucasin was dissolved in dimethyl sulfoxide (DMSO, Sigma, D8418, St. Louis, MO, USA) and IAA was dissolved in EtOH (J. T. Baker, Thermo Fisher Scientific, Phillipsburg, NJ, USA). As a control, DMSO was added to the semisolid pre-treatment medium. The experiments were performed in biological triplicate. The effects of the different concentrations of the yucasin were analyzed by quantifying the number of embryos formed after 56 days.

\subsection{Plant Tissue Sampling}

The plant tissue samples were collected at different times from Days 0 (D0), 7 (D7), 14 (D14), 21 (D21), and 28 (D28). Samples collected 0, 7, 14, 21, and 28 dai of SE were used for performing immunolocalization assays. Days -14 (at the beginning of the pre-treatment), 0, 7, 14, 21, 28 dai were used for analysis of quantitative genetic expression. 


\subsection{Real-Time Quantitative Analysis of Gene Expression}

The total RNA extraction was performed following the manufacture's instructions for TRI reagent (Sigma, 93298, St. Louis, MO, USA). A total $100 \mathrm{mg}$ of plant tissue was used for RNA extraction. The integrity and purity of the RNA was evaluated by $1 \%$ agarose electrophoresis and spectrophotometry (NanoDrop 2000, Thermo Scientific). Five milligrams of total RNA was used for cDNA (complementary DNA) synthesis using a Super Script II reverse transcriptase kit (Invitrogen) following the manufacturer's protocol. Quantification of gene expressions by qRT-PCR were carried out with Appied Biosystems equipment using the Step One program. The Coffee "Genome" Hub page was consulted (http://coffee-genome.org/) and the genome database of C. canephora was downloaded for the design of specific primers described in Supplementary Table S1 to analyze the YUCCA genes. With the support of the C. canephora transcriptome [37], an analysis was carried out to determine which genes could be the main participants during the induction process of SE. After identifying the YUC candidate genes, the coding sequences (CDS) of the specific genes were downloaded and the design of the primers was carried out in the Primer3plus program (http://www.bioinformatics.nl/cgi-bin/primer3plus/primer3plus.cgi/). The primers for each gene were tested via in situ PCR in Sol Genomics (http://solgenomics.net/).

\subsection{Histological Analyses}

The plant tissues were fixed in FAA solution (10\% formaldehyde (Fischer BioReagents, BP531, Pittsburgh, PA, USA), 5\% acetic acid (Sigma, 695092, St. Louis, MO, USA), and 50\% ethanol (Meyer, 0390, CDMX, Meixo)) for $72 \mathrm{~h}$ in dark conditions at $4{ }^{\circ} \mathrm{C}$. A gradient of sucrose $(10,20,30 \%)$ was made to embed the samples in a PB buffer (10 mM sodium phosphate dibasic (Sigma, S3264, St. Louis, MO, USA) and $2 \mathrm{mM}$ potassium phosphate monobasic (Sigma, P5655, St. Louis, MO, USA)), pH 7.2 (adjusted with $\mathrm{NaOH} 1 \mathrm{~N}$ ), adding three to six drops of Leica tissue-freezing medium (Leica Biosystem, Code 14020108926, Guadalajara, Mexico) to the gradients of 20 and 30\%, respectively. Each gradient was changed after $1 \mathrm{~h}$ at $4{ }^{\circ} \mathrm{C}$. Subsequently, the samples were embedded in a Leica tissue-freezing medium (Leica Biosystem, Code 14020108926, Guadalajara, Mexico) at $-26{ }^{\circ} \mathrm{C}$. The blocks were sectioned at $30 \mu \mathrm{m}$ with a cryostat (Leica Biosystem CM1950, Guadalajara, Mexico) with low-profile blades (Thermo Scientific, 1407060, Thermo Fisher Scientific, NJ, USA). The samples were stained with calcofluor white (18909-1000 ML-F Fluka Analytical Sigma-Aldrich, St. Louis, MO, USA) for $1 \mathrm{~h}$. The images were obtained using a confocal laser scanning microscope (Olympus, FV1000 SW, Tokyo, Japan) and the FV10 ASW 3.1 viewer software. The calcofluor white signal was detected using the excitation wavelength of $380 \mathrm{~nm}$; the emission wavelength was $475 \mathrm{~nm}$. Sections of $30 \mu \mathrm{m}$ were collected on glass slides. Images were taken with a microscope Axio Lab.A1 MAT HAL 50 (AXIOPLAN 490951-0002-000) and the Axiovision SE 64 Rel 4.8 viewer software.

\subsection{Immunolocalization Assays}

Immunofluorescence was assessed with modifications of the protocols previously described [2,39]. In this method, we eliminated the use of paraffin and replaced it with the Leica tissue-freezing medium (Leica Biosystem, Code 14020108926, Buffalo Grove, IL, USA) to embed the tissues. In addition, we did not use the sodium citrate buffer, Tween, and we skipped the heating step of the slides. In short, the slides with sample tissue (previously rinsed with $0.1 \%$ poly-L-lysine in $\mathrm{H}_{2} \mathrm{O}$ ) were washed three times with sterile distilled water to remove excess Leica tissue-freezing medium, and then washed three time with the PB buffer, pH 7.2 (adjusted with $\mathrm{NaOH} 1 \mathrm{~N}$ ). Sections were blocked with $3 \%$ bovine serum albumin (BSA, Sigma, A2153, St. Louis, MO, USA) in PB for $1 \mathrm{~h}$ at $4{ }^{\circ} \mathrm{C}$. After three rinses with $\mathrm{PB}$, sections were incubated overnight with anti-IAA mouse monoclonal antibody (Sigma, A0855, St. Louis, MO, USA) diluted 1:100 in 1\% BSA in PB buffer. After three rinses with PB buffer, sections were incubated for $3 \mathrm{~h}$ in darkness with Alexa Fluor 488-labeled anti-mouse IgG antibody (Invitrogen, A-11,001, Carlsbad, CA, USA) diluted 1:100 in PB. After three washes with PB buffer, the 
tissue sections were treated with $10 \mu \mathrm{L}$ of Vectashield mounting medium and DAPI to stain the DNA (Vector Laboratories, H-1200, Burlingame, CA, USA) and stored in the dark for $1 \mathrm{~h}$ at $4{ }^{\circ} \mathrm{C}$. The images were obtained using a confocal laser scanning microscope (Olympus, FV1000 SW, Tokyo, Japan) and the FV10 ASW 3.1 viewer software. The IAA signal was detected using an excitation wavelength of $488 \mathrm{~nm}$; the emission wavelength was $520 \mathrm{~nm}$. The DAPI staining signal was detected using the excitation wavelength of $405 \mathrm{~nm}$; the emission wavelength was $461 \mathrm{~nm}$. The immunolocalization assay experiments were performed independently three times.

\subsection{Controls of IAA Immunolocalization}

Negative controls were performed by replacing the antibody first by PB buffer. The anti-IAA mouse antibody was incubated with a solution of $5 \mathrm{mg} \mathrm{mL}^{-1}$ synthetic IAA at a 1:2 (v/v) ratio at $4{ }^{\circ} \mathrm{C}$ overnight; the pre-blocked antibody solution was used as the primary antibody for immunofluorescence, following the same protocol and conditions as described above.

\subsection{Statistical Analysis}

The data processing to make the graphs and the statistical analyses were done with the ANOVA variance analysis program using the Origin Pro 201764 bit software, ver. 94E (Data Analysis and Graphing Software). Significance values were determined using the Tukey test. The differences were considered significant at $p \leq 0.05$.

\section{Conclusions}

In this study, we demonstrated that the auxin IAA is crucial during the SE induction process in C. canephora. The data presented describe the expression of the YUC genes on Day 0 of the SE induction process. The location of free IAA on Day 0 was consistent with the analysis of gene expression, suggesting de novo biosynthesis of IAA. Additionally, exogenous application of yucasin inhibited IAA synthesis and blocked SE. In conclusion, the expression levels, the location of IAA, and the use of the yucasin inhibitor in this investigation provide valuable information for understanding IAA biosynthesis during the SE induction process in C. canephora.

Supplementary Materials: Supplementary Materials can be found at http:/www.mdpi.com/1422-0067/21/13/ 4751/s1.

Author Contributions: Conceptualization, V.M.L.-V.; methodology, M.A.U.-C., C.P.-H., R.M.G.-Á., L.B.-A., V.A.-H.; formal analysis, V.M.L.-V., V.A.-H.; investigation, M.A.U.-C.; resources, V.M.L.-V.; writing-original draft preparation, M.A.U.-C.; writing—review and editing, V.M.L.-V.; supervision, V.M.L.-V.; project administration, V.M.L.-V.; funding acquisition, V.M.L.-V. All authors have read and agreed to the published version of the manuscript.

Funding: This research was supported by Consejo Nacional de Ciencia y Tecnología CONACYT grant (Grant 1515).

Acknowledgments: We would like thank Angela Ku-Gonzalez for her technical support in the confocal microscope and to Irma Angelica Jiménez-Ramírez for her support in histology.

Conflicts of Interest: The authors declare no conflict of interest.

\section{Abbreviations}

$\begin{array}{ll}\text { DAI } & \text { Days after induction } \\ \text { IAA } & \text { Indole-3-acetic acid } \\ \text { IPA } & \text { Indole-3-pyruvic acid } \\ \text { Kin } & \text { Kinetin } \\ \text { NAA } & \text { Naphthalenacetic acid } \\ \text { SE } & \text { Somatic embryogenesis } \\ \text { Trp } & \text { Tryptophan }\end{array}$




\section{References}

1. Vogel, G. How Does a Single Somatic Cell Become a Whole Plant? Science 2005, 309, 86. [CrossRef] [PubMed]

2. Nic-Can, G.I.; Lopez-Torres, A.; Barredo-Pool, F.; Wróbel, K.; Loyola-Vargas, V.M.; Rojas-Herrera, R.; De-La-Peña, C. New Insights into Somatic Embryogenesis: LEAFY COTYLEDON1, BABY BOOM1 and WUSCHEL-RELATED HOMEOBOX4 Are Epigenetically Regulated in Coffea canephora. PLoS ONE 2013, 8, e72160. [CrossRef] [PubMed]

3. E Tvorogova, V.; Fedorova, Y.A.; Potsenkovskaya, E.A.; Kudriashov, A.A.; Efremova, E.P.; Kvitkovskaya, V.A.; Wolabu, T.W.; Zhang, F.; Tadege, M.; Lutova, L.A. The WUSCHEL-related homeobox transcription factor MtWOX9-1 stimulates somatic embryogenesis in Medicago truncatula. Plant Cell Tissue Organ Cult. (PCTOC) 2019, 138, 517-527. [CrossRef]

4. Loyola-Vargas, V.M.; Ochoa-Alejo, N. Somatic Embryogenesis. An Overview. In Somatic Embryogenesis: Fundamental Aspects and Applications; Springer: Berlin/Heidelberg, Germany, 2016; pp. 1-8.

5. Quiroz-Figueroa, F.; Rojas-Herrera, R.; Galaz-Ávalos, R.M.; Loyola-Vargas, V.M. Embryo production through somatic embryogenesis can be used to study cell differentiation in plants. Plant Cell Tissue Organ Cult. (PCTOC) 2006, 86, 285-301. [CrossRef]

6. Ma, Q.; Zhou, W.; Zhang, P. Transition from somatic embryo to friable embryogenic callus in cassava: Dynamic changes in cellular structure, physiological status, and gene expression profiles. Front. Plant Sci. 2015, 6, 986. [CrossRef]

7. Santana, N.; Gonzalez, M.E.; Valcarcel, M.; Canto-Flick, A.; Hernández, M.M.; Fuentes-Cerda, F.J.; Barahona, F.; Mijangos-Cortes, J.; Loyola-Vargas, V.M. Somatic embryogenesis: A valuable alternative for propagating selected robusta coffee (Coffea canephora) clones. Vitr. Cell. Dev. Boil. Anim. 2004, 40, 95-101. [CrossRef]

8. Magnani, E.; Jiménez-Gómez, J.M.; Soubigou-Taconnat, L.; Lepiniec, L.; Fiume, E. Profiling the onset of somatic embryogenesis in Arabidopsis. BMC Genom. 2017, 18, 998. [CrossRef] [PubMed]

9. Quiroz-Figueroa, F.; Méndez-Zeel, M.; Saavedra, A.L.; Loyola-Vargas, V. Picomolar concentrations of salicylates induce cellular growth and enhance somatic embryogenesis in Coffea arabica tissue culture. Plant Cell Rep. 2001, 20, 679-684. [CrossRef]

10. Fuentes-Cerda, C.; Monforte-González, M.; Méndez-Zeel, M.; Rojas-Herrera, R.; Loyola-Vargas, V.M. Modification of the embryogenic response of Coffea arabica by the nitrogen source. Biotechnol. Lett. 2001, 23, 1341-1343. [CrossRef]

11. Quiroz-Figueroa, F.; Fuentes-Cerda, C.; Rojas-Herrera, R.; Loyola-Vargas, V. Histological studies on the developmental stages and differentiation of two different somatic embryogenesis systems of Coffea arabica. Plant Cell Rep. 2002, 20, 1141-1149. [CrossRef]

12. De-La-Peña, C.; Nic-Can, G.I.; Galaz-Ávalos, R.M.; Avilez-Montalvo, R.; Loyola-Vargas, V.M. The role of chromatin modifications in somatic embryogenesis in plants. Front. Plant Sci. 2015, 6, 383. [CrossRef] [PubMed]

13. Dudits, D.; Bögre, L.; Györgyey, J. Molecular and cellular approaches to the analysis of plant embryo development from somatic cells in vitro. J. Cell Sci. 1991, 99, 473-482.

14. Tsugafune, S.; Mashiguchi, K.; Fukui, K.; Takebayashi, Y.; Nishimura, T.; Sakai, T.; Shimada, Y.; Kasahara, H.; Koshiba, T.; Hayashi, K.-I. Yucasin DF, a potent and persistent inhibitor of auxin biosynthesis in plants. Sci. Rep. 2017, 7, 13992. [CrossRef] [PubMed]

15. Nonhebel, H.M. Tryptophan-Independent Indole-3-Acetic Acid Synthesis: Critical Evaluation of the Evidence. Plant Physiol. 2015, 169, 1001-1005. [CrossRef] [PubMed]

16. Paque, S.; Weijers, D. Q\&A: Auxin: The plant molecule that influences almost anything. BMC Boil. 2016, 14, 67. [CrossRef]

17. Petrášek, J.; Friml, J. Auxin transport routes in plant development. Development 2009, 136, $2675-2688$. [CrossRef]

18. Peer, W.A.; Blakeslee, J.J.; Yang, H.; Murphy, A.S. Seven Things We Think We Know about Auxin Transport. Mol. Plant 2011, 4, 487-504. [CrossRef]

19. Zhao, Y.; Christensen, S.K.; Fankhauser, C.; Cashman, J.R.; Cohen, J.D.; Weigel, D.; Chory, J. A Role for Flavin Monooxygenase-Like Enzymes in Auxin Biosynthesis. Science 2001, 291, 306-309. [CrossRef] [PubMed] 
20. Stepanova, A.N.; Yun, J.; Robles, L.M.; Novak, O.; He, W.; Guo, H.; Ljung, K.; Alonso, J.M. The Arabidopsis YUCCA1 Flavin Monooxygenase Functions in the Indole-3-Pyruvic Acid Branch of Auxin Biosynthesis. Plant Cell 2011, 23, 3961-3973. [CrossRef] [PubMed]

21. Mashiguchi, K.; Tanaka, K.; Sakai, T.; Sugawara, S.; Kawaide, H.; Natsume, M.; Hanada, A.; Yaeno, T.; Shirasu, K.; Yao, H.; et al. The main auxin biosynthesis pathway in Arabidopsis. Proc. Natl. Acad. Sci. USA 2011, 108, 18512-18517. [CrossRef]

22. Zhao, Y. Auxin Biosynthesis. Arab. Book 2014, 12, e0173. [CrossRef] [PubMed]

23. Brumos, J.; Alonso, J.M.; Stepanova, A.N. Genetic aspects of auxin biosynthesis and its regulation. Physiol. Plant. 2013, 151, 3-12. [CrossRef]

24. Cheng, Y.; Dai, X.; Zhao, Y. Auxin Synthesized by the YUCCA Flavin Monooxygenases Is Essential for Embryogenesis and Leaf Formation in Arabidopsis. Plant Cell 2007, 19, 2430-2439. [CrossRef] [PubMed]

25. Zhao, Y. Auxin Biosynthesis and Its Role in Plant Development. Annu. Rev. Plant Boil. 2010, 61, 49-64. [CrossRef] [PubMed]

26. Cheng, Y.; Dai, X.; Zhao, Y. Auxin biosynthesis by the YUCCA flavin monooxygenases controls the formation of floral organs and vascular tissues in Arabidopsis. Genome Res. 2006, 20, 1790-1799. [CrossRef] [PubMed]

27. Cohen, J.D.; Hu, W.-S.; Ribnicky, D.M.; Cooke, T.J. An auxin surge following fertilization in carrots: A mechanism for regulating plant totipotency. Planta 2002, 214, 505-509. [CrossRef]

28. Nishimura, T.; Hayashi, K.-I.; Suzuki, H.; Gyohda, A.; Takaoka, C.; Sakaguchi, Y.; Matsumoto, S.; Kasahara, H.; Sakai, T.; Kato, J.-I.; et al. Yucasin is a potent inhibitor of YUCCA, a key enzyme in auxin biosynthesis. Plant J. 2014, 77, 352-366. [CrossRef]

29. Rampey, R.A.; LeClere, S.; Kowalczyk, M.; Ljung, K.; Sandberg, G.; Bartel, B. A Family of Auxin-Conjugate Hydrolases That Contributes to Free Indole-3-Acetic Acid Levels during Arabidopsis Germination1. Plant Physiol. 2004, 135, 978-988. [CrossRef]

30. Zhang, J.; Peer, W.A. Auxin homeostasis: The DAO of catabolism. J. Exp. Bot. 2017, 68, 3145-3154. [CrossRef]

31. Sugawara, S.; Hishiyama, S.; Jikumaru, Y.; Hanada, A.; Nishimura, T.; Koshiba, T.; Zhao, Y.; Kamiya, Y.; Kasahara, H. Biochemical analyses of indole-3-acetaldoxime-dependent auxin biosynthesis in Arabidopsis. Proc. Natl. Acad. Sci. USA 2009, 106, 5430-5435. [CrossRef]

32. Zhao, Y.; Hull, A.K.; Gupta, N.R.; Goss, K.A.; Alonso, J.M.; Ecker, J.R.; Normanly, J.; Chory, J.; Celenza, J.L. Trp-dependent auxin biosynthesis in Arabidopsis: Involvement of cytochrome P450s CYP79B2 and CYP79B3. Genome Res. 2002, 16, 3100-3112. [CrossRef] [PubMed]

33. Hull, A.K.; Vij, R.; Celenza, J.L. Arabidopsis cytochrome P450s that catalyze the first step of tryptophan-dependent indole-3-acetic acid biosynthesis. Proc. Natl. Acad. Sci. USA 2000, 97, 2379-2384. [CrossRef] [PubMed]

34. Liu, X.; Hegeman, A.D.; Gardner, G.; Cohen, J.D. Protocol: High-throughput and quantitative assays of auxin and auxin precursors from minute tissue samples. Plant Methods 2012, 8, 31. [CrossRef] [PubMed]

35. Zhao, Y. Essential Roles of Local Auxin Biosynthesis in Plant Development and in Adaptation to Environmental Changes. Annu. Rev. Plant Boil. 2018, 69, 417-435. [CrossRef] [PubMed]

36. Denoeud, F.; Carretero-Paulet, L.; Dereeper, A.; Droc, G.; Guyot, R.; Pietrella, M.; Zheng, C.; Alberti, A.; Anthony, F.; Aprea, G.; et al. The coffee genome provides insight into the convergent evolution of caffeine biosynthesis. Science 2014, 345, 1181-1184. [CrossRef]

37. Quintana-Escobar, A.O.; Nic-Can, G.I.; Avalos, R.M.G.; Loyola-Vargas, V.M.; Góngora-Castillo, E. Transcriptome analysis of the induction of somatic embryogenesis in Coffea canephora and the participation of ARF and Aux/IAA genes. PeerJ 2019, 7, e7752. [CrossRef]

38. Rodríguez-Sanz, H.; Solís, M.-T.; López, M.-F.; Gómez-Cadenas, A.; Risueño, M.C.; Testillano, P.S. Auxin Biosynthesis, Accumulation, Action and Transport are Involved in Stress-Induced Microspore Embryogenesis Initiation and Progression inBrassica napus. Plant Cell Physiol. 2015, 56, 1401-1417. [CrossRef]

39. Márquez-López, R.E.; Pérez-Hernández, C.; Ku-González, Á.; Galaz-Ávalos, R.M.; Loyola-Vargas, V.M. Localization and transport of indole-3-acetic acid during somatic embryogenesis in Coffea canephora. Protoplasma 2017, 255, 695-708. [CrossRef]

40. Zhao, Y. Auxin biosynthesis: A simple two-step pathway converts tryptophan to indole-3-acetic acid in plants. Mol. Plant 2011, 5, 334-338. [CrossRef] 
41. Ayil-Gutiérrez, B.; Galaz-Ávalos, R.M.; Peña-Cabrera, E.; Loyola-Vargas, V.M. Dynamics of the concentration of IAA and some of its conjugates during the induction of somatic embryogenesis inCoffea canephora. Plant Signal. Behav. 2013, 8, e26998. [CrossRef]

42. Balzan, S.; Johal, G.S.; Carraro, N. The role of auxin transporters in monocots development. Front. Plant Sci. 2014, 5, 393. [CrossRef] [PubMed]

43. Wójcikowska, B.; Gaj, M.D. Somatic Embryogenesis in Arabidopsis. In Somatic Embryogenesis: Fundamental Aspects and Applications; Springer: Berlin/Heidelberg, Germany, 2016; pp. 185-199.

44. Kumar, P.; Srivastava, D.K. Biotechnological applications in in vitro plant regeneration studies of broccoli (Brassica oleracea L. var. italica), an important vegetable crop. Biotechnol. Lett. 2015, 38, 561-571. [CrossRef]

45. Rose, R.J. Somatic Embryogenesis in the Medicago truncatula Model: Cellular and Molecular Mechanisms. Front. Plant Sci. 2019, 10, 267. [CrossRef] [PubMed]

46. Loyola-Vargas, V.M.; Avilez-Montalvo, J.R.; Aviles-Montalvo, R.N.; Márquez-López, R.E.; Galaz-Ávalos, R.M.; Mellado-Mojica, E. Somatic Embryogenesis in Coffea spp. In Somatic Embryogenesis: Fundamental Aspects and Applications; Springer: Berlin/Heidelberg, Germany, 2016; pp. 241-266.

47. Pais, M.S. Somatic Embryogenesis Induction in Woody Species: The Future After OMICs Data Assessment. Front. Plant Sci. 2019, 10, 240. [CrossRef] [PubMed]

48. Aguilar-Hernández, V.; Loyola-Vargas, V.M. Advanced Proteomic Approaches to Elucidate Somatic Embryogenesis. Front. Plant Sci. 2018, 9, 9. [CrossRef] [PubMed]

49. Benkova, E.; Michniewicz, M.; Sauer, M.; Teichmann, T.; Seifertová, D.; Jürgens, G.; Friml, J. Local, Efflux-Dependent Auxin Gradients as a Common Module for Plant Organ Formation. Cell 2003, 115, 591-602. [CrossRef]

50. De Vega, J.; Santos, R.R.; Simões, M.; Miguel, C.M. Normalizing gene expression by quantitative PCR during somatic embryogenesis in two representative conifer species: Pinus pinaster and Picea abies. Plant Cell Rep. 2013, 32, 715-729. [CrossRef]

51. Weijers, D.; Wagner, R. Transcriptional Responses to the Auxin Hormone. Annu. Rev. Plant Boil. 2016, 67, 539-574. [CrossRef]

52. Méndez-Hernández, H.A.; Ledezma-Rodríguez, M.; Avilez-Montalvo, R.N.; Juárez-Gómez, Y.L.; Skeete, A.; Avilez-Montalvo, J.; De-La-Peña, C.; Loyola-Vargas, V.M. Signaling Overview of Plant Somatic Embryogenesis. Front. Plant Sci. 2019, 10, 77. [CrossRef] [PubMed]

53. Berthouly, M.; Michaux-Ferriere, N.M. High frequency somatic embryogenesis in Coffea canephora. Plant Cell Tissue Organ Cult. (PCTOC) 1996, 44, 169-176. [CrossRef]

54. Santana-Buzzy, N.; Rojas-Herrera, R.; Galaz-Ávalos, R.M.; Ku-Cauich, J.R.; Mijangos-Cortés, J.; Gutiérrez-Pacheco, L.C.; Canto, A.; Quiroz-Figueroa, F.; Loyola-Vargas, V.M. Advances in coffee tissue culture and its practical applications. Vitr. Cell. Dev. Boil. Anim. 2007, 43, 507-520. [CrossRef]

55. Tahara, M.; Nakanishi, T.; Yasuda, T.; Yamaguchi, T. Histological and biological aspects in somatic embryogenesis of Coffea arabica. In 16è Colloque Scientifique Internationale sur le Café; Association Scientifique Internationale du Café: Paris, France, 1995; pp. 860-867.

56. Liu, J.; Sheng, L.; Xu, Y.; Li, J.; Yang, Z.; Huang, H.; Xu, L. WOX11 and 12 Are Involved in the First-Step Cell Fate Transition during de Novo Root Organogenesis in Arabidopsis. Plant Cell 2014, 26, 1081-1093. [CrossRef] [PubMed]

57. Chen, L.; Tong, J.; Xiao, L.; Ruan, Y.; Liu, J.; Zeng, M.; Huang, H.; Wang, J.-W.; Xu, L. YUCCA-mediated auxin biogenesis is required for cell fate transition occurring during de novo root organogenesis in Arabidopsis. J. Exp. Bot. 2016, 67, 4273-4284. [CrossRef] [PubMed]

58. Woodward, A.; Bartel, B. Auxin: Regulation, Action, and Interaction. Ann. Bot. 2005, 95, 707-735. [CrossRef] [PubMed]

59. Kasahara, H. Current aspects of auxin biosynthesis in plants. Biosci. Biotechnol. Biochem. 2015, 80, 34-42. [CrossRef] [PubMed]

60. Bernardi, J.; Lanubile, A.; Li, Q.-B.; Kumar, D.; Kladnik, A.; Cook, S.D.; Ross, J.J.; Marocco, A.; Chourey, P.S. Impaired auxin biosynthesis in the defective endosperm 18 mutant is due to mutational loss of expression in the ZmYuc1 gene encoding endosperm-specific YUCCA1 protein in maize. Plant Physiol. 2012, 160, 1318-1328. [CrossRef] 
61. Sitbon, F.; Åstot, C.; Edlund, A.; Crozier, A.; Sandberg, G. The relative importance of tryptophan-dependent and tryptophan-independent biosynthesis of indole-3-acetic acid in tobacco during vegetative growth. Planta 2000, 211, 715-721. [CrossRef]

62. Wang, B.; Chu, J.; Yu, T.; Xu, Q.; Sun, X.; Yuan, J.; Xiong, G.; Wang, G.; Wang, Y.; Li, J. Tryptophan-independent auxin biosynthesis contributes to early embryogenesis in Arabidopsis. Proc. Natl. Acad. Sci. USA 2015, 112, 4821-4826. [CrossRef]

63. Gallei, M.; Luschnig, C.; Friml, J. Auxin signalling in growth: Schrödinger's cat out of the bag. Curr. Opin. Plant Boil. 2020, 53, 43-49. [CrossRef]

64. Bennett, T.; Leyser, O. The Auxin Question: A Philosophical Overview. In Auxin and Its Role in Plant Development; Springer: Berlin/Heidelberg, Germany, 2014; pp. 3-19.

65. Petrášek, J.; Malínská, K.; Zazimalova, E. Auxin Transporters Controlling Plant Development. In Ion Channels and Plant Stress Responses; Springer: Berlin/Heidelberg, Germany, 2010; Volume 7, pp. 255-290.

66. Zazimalova, E.; Křeček, P.; Skupa, P.; Hoyerová, K.; Petrášek, J. Polar transport of the plant hormone auxin-The role of PIN-FORMED (PIN) proteins. Cell. Mol. Life Sci. 2007, 64, 1621-1637. [CrossRef]

67. Naramoto, S. Polar transport in plants mediated by membrane transporters: Focus on mechanisms of polar auxin transport. Curr. Opin. Plant Boil. 2017, 40, 8-14. [CrossRef] [PubMed]

68. Křeček, P.; Skůpa, P.; Libus, J.; Naramoto, S.; Tejos, R.; Friml, J.; Zazimalova, E. The PIN-FORMED (PIN) protein family of auxin transporters. Genome Boil. 2009, 10, 249. [CrossRef] [PubMed]

69. Korasick, D.A.; A Enders, T.; Strader, L.C. Auxin biosynthesis and storage forms. J. Exp. Bot. 2013, 64, 2541-2555. [CrossRef] [PubMed]

70. Westfall, C.S.; Herrmann, J.; Chen, Q.; Wang, S.; Jez, J.M. Modulating plant hormones by enzyme action. Plant Signal. Behav. 2010, 5, 1607-1612. [CrossRef] [PubMed]

71. Bartel, B.; Fink, G. ILR1, an amidohydrolase that releases active indole-3-acetic acid from conjugates. Science 1995, 268, 1745-1748. [CrossRef] [PubMed]

72. LeClere, S.; Tellez, R.; Rampey, R.A.; Matsuda, S.P.T.; Bartel, B. Characterization of a Family of IAA-Amino Acid Conjugate Hydrolases fromArabidopsis. J. Boil. Chem. 2002, 277, 20446-20452. [CrossRef]

73. Quint, M.; Gray, W.M. Auxin signaling. Curr. Opin. Plant Boil. 2006, 9, 448-453. [CrossRef]

74. Tang, Q.; Yu, P.; Tillmann, M.; Cohen, J.D.; Slovin, J.P. Indole-3-acetylaspartate and indole-3-acetylglutamate, the IAA-amide conjugates in the diploid strawberry achene, are hydrolyzed in growing seedlings. Planta 2018, 249, 1073-1085. [CrossRef]

75. Patten, C.L.; Glick, B.R. Bacterial biosynthesis of indole-3-acetic acid. Can. J. Microbiol. 1996, 42, $207-220$. [CrossRef]

76. Mikkelsen, M.D.; Hansen, C.H.; Wittstock, U.; Halkier, B.A. Cytochrome P450 CYP79B2 from Arabidopsis Catalyzes the Conversion of Tryptophan to Indole-3-acetaldoxime, a Precursor of Indole Glucosinolates and Indole-3-acetic Acid. J. Boil. Chem. 2000, 275, 33712-33717. [CrossRef]

77. Eklund, D.M.; Ishizaki, K.; Flores-Sondoval, E.; Kikuchi, S.; Takebayashi, Y.; Tsukamoto, S.; Hirakawa, Y.; Nonomura, M.; Kato, H.; Kouno, M.; et al. Auxin Produced by the Indole-3-Pyruvic Acid Pathway Regulates Development and Gemmae Dormancy in the Liverwort Marchantia polymorpha[OPEN]. Plant Cell 2015, 27, 1650-1669. [CrossRef] [PubMed]

78. Murashige, T.; Skoog, F. A Revised Medium for Rapid Growth and Bio Assays with Tobacco Tissue Cultures. Physiol. Plant. 1962, 15, 473-497. [CrossRef]

79. Yasuda, T.; Fujii, Y.; Yamaguchi, T. Embryogenic Callus Induction from Coffea arabica Leaf Explants by Benzyladenine. Plant Cell Physiol. 1985, 26, 595-597. [CrossRef]

80. Quiroz-Figueroa, F.; Monforte-González, M.; Galaz-Ávalos, R.M.; Loyola-Vargas, V.M.; Vázquez-Flota, F. Direct Somatic Embryogenesis in Coffea canephora. In Plant Cell Culture Protocols; Springer: Berlin/Heidelberg, Germany, 2005; Volume 318, pp. 111-118.

(C) 2020 by the authors. Licensee MDPI, Basel, Switzerland. This article is an open access article distributed under the terms and conditions of the Creative Commons Attribution (CC BY) license (http://creativecommons.org/licenses/by/4.0/). 